\title{
Medievalista
}

Online

$30 \mid 2021$

Número 30

\section{El linaje catalán Queralt-Timor y su relación con la Orden del Temple (siglos XII-XIV)}

The catalan Queralt-Timor lineage and its relationship with the Order of the Temple (12th-14th centuries)

Joan Fuguet Sans y Carme Plaza Arqué

\section{CpenEdition}

\section{Journals}

Edición electrónica

URL: https://journals.openedition.org/medievalista/4514

DOI: 10.4000/medievalista.4514

ISSN: 1646-740X

Editor

Instituto de Estudos Medievais - FCSH-UNL

\section{Referencia electrónica}

Joan Fuquet Sans y Carme Plaza Arqué, «El linaje catalán Queralt-Timor y su relación con la Orden del Temple (siglos XII-XIV)», Medievalista [En línea], 30 | 2021, Publicado el 01 julio 2021, consultado el 24 julio 2021. URL: http://journals.openedition.org/medievalista/4514 ; DOI: https://doi.org/10.4000/ medievalista.4514

Este documento fue generado automáticamente el 24 julio 2021.

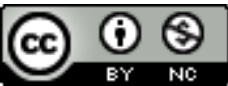

Mediavalista está licenciado com uma Licença Creative Commons - Atribuição-NãoComercial 4.0 Internacional. 


\section{El linaje catalán Queralt-Timor y su relación con la Orden del Temple (siglos XII-XIV)}

The catalan Queralt-Timor lineage and its relationship with the Order of the Temple (12th-14th centuries)

Joan Fuguet Sans y Carme Plaza Arqué

\section{NOTA DEL EDITOR}

Data recepção do artigo / Received for publication: 1 de Dezembro de 2020

Data aceitação do artigo / Accepted in revised form: 18 de Março de 2021

1 El objetivo de este artículo es presentar una familia noble catalana del siglo XIII que proporcionó importantes personajes a la orden del Temple, al tiempo que recorrer los parentescos que ella estableció con otras familias también nobles, entre cuyos miembros se cuentan importantes dignatarios de la Orden. La familia Queralt-Timor y su relación con el Temple será el tema principal de este trabajo.

2 Muchos estudios han tratado de la relación de los linajes nobles con el Temple ${ }^{1}$. Sin embargo, resulta difícil generalizar, ya que las valoraciones pueden variar según el territorio y la época ${ }^{2}$ (Fig. 1). 


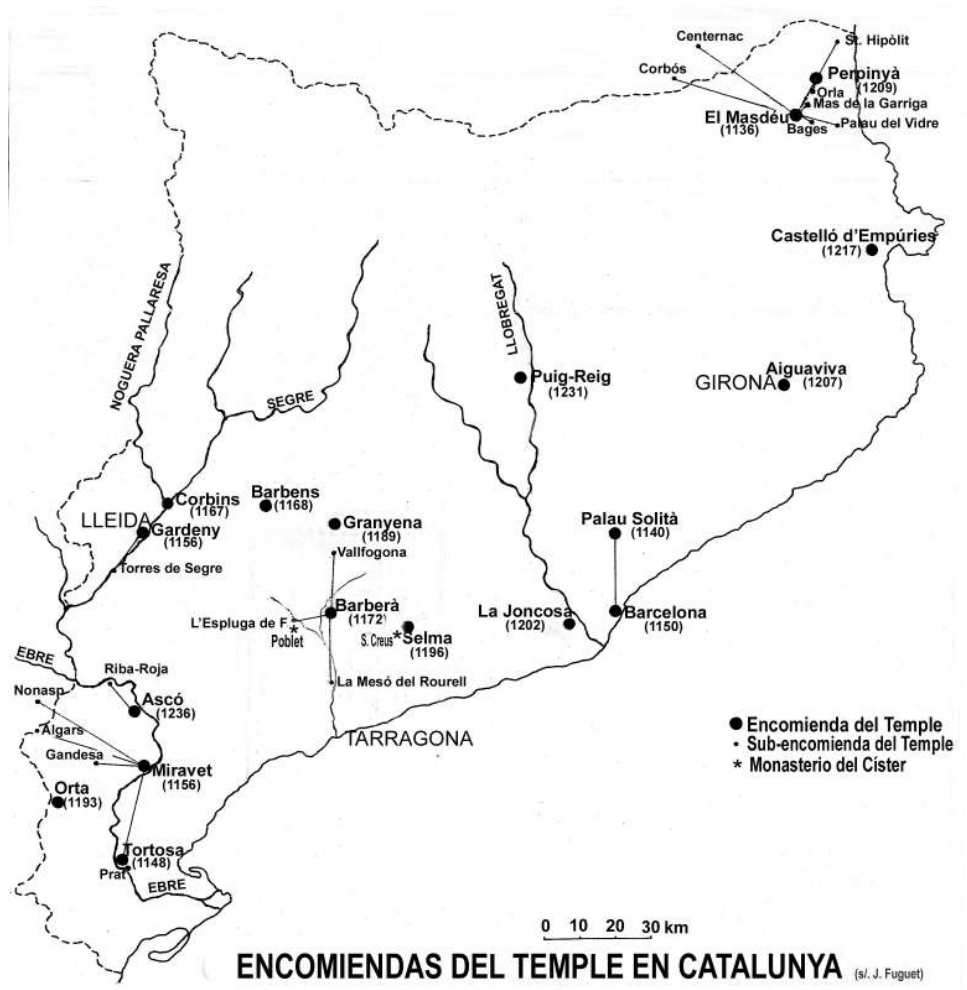

Fig. 1 - Encomiendas de la orden del Temple en Catalunya.

Dibujo, Joan Fuguet.

Por lo que respecta a la corona catalano-aragonesa, Forey constata que el cargo de Maestre Provincial estuvo casi siempre ocupado por miembros de familias de la alta nobleza: Torroja, Cardona, Castellnou, Rovira, hecho que muestra hasta qué punto el linaje y la posición social eran determinantes en los $\operatorname{cargos}^{3}$. Sin embargo, otras familias nobles cuyos miembros desempeñaron importantes carreras en la orden resultan prácticamente desconocidas. Un ejemplo paradigmático lo constituye la familia Queralt ${ }^{4}$ y sus diferentes ramas Timor, Oluja.

Hemos tratado el linaje de los Queralt desde tres enfoques: por un lado, como benefactores en la creación de las encomiendas, en segundo lugar como miembros de la familia templaria, ya sea como donados o frailes, y, en tercer lugar, y no menos importante, como una aristocracia guerrera al servicio de la Orden y de la Corona.

Las encomiendas del Temple en la primera Marca

Es de sobras conocido que la primera donación al Temple en territorio catalán es la donación del castillo de Granyena realizada el 1130 o $1131^{5}$ por Ramon Berenguer III, conde de Barcelona, quien también profesó en la Orden. Siguiendo su ejemplo, el conde de Urgell, Ermengol IV, un año después donaba al Temple el castillo de Barberà (de la Conca). Esta donación se vería completada cuando en 1133 el joven Ramon Berenguer IV les cedió su parte de dominio sobre Barberà ${ }^{6}$. La donación temprana de estas tierras por parte de los condes de Barcelona y Urgell muestra la inequívoca decisión de involucrar al Temple en la conquista. Por lo tanto, a pesar de ser donaciones tempranas, las encomiendas catalanas (excepto la del Masdéu ${ }^{7}$, en el Rosselló) no se constituyeron como tales hasta la conquista y consolidación de las principales plazas y castillos de frontera: Tortosa - Miravet (1148-1153) en el Ebro, y Lleida - Gardeny (1149), en el Segre ${ }^{8}$ (Fig. 2). 


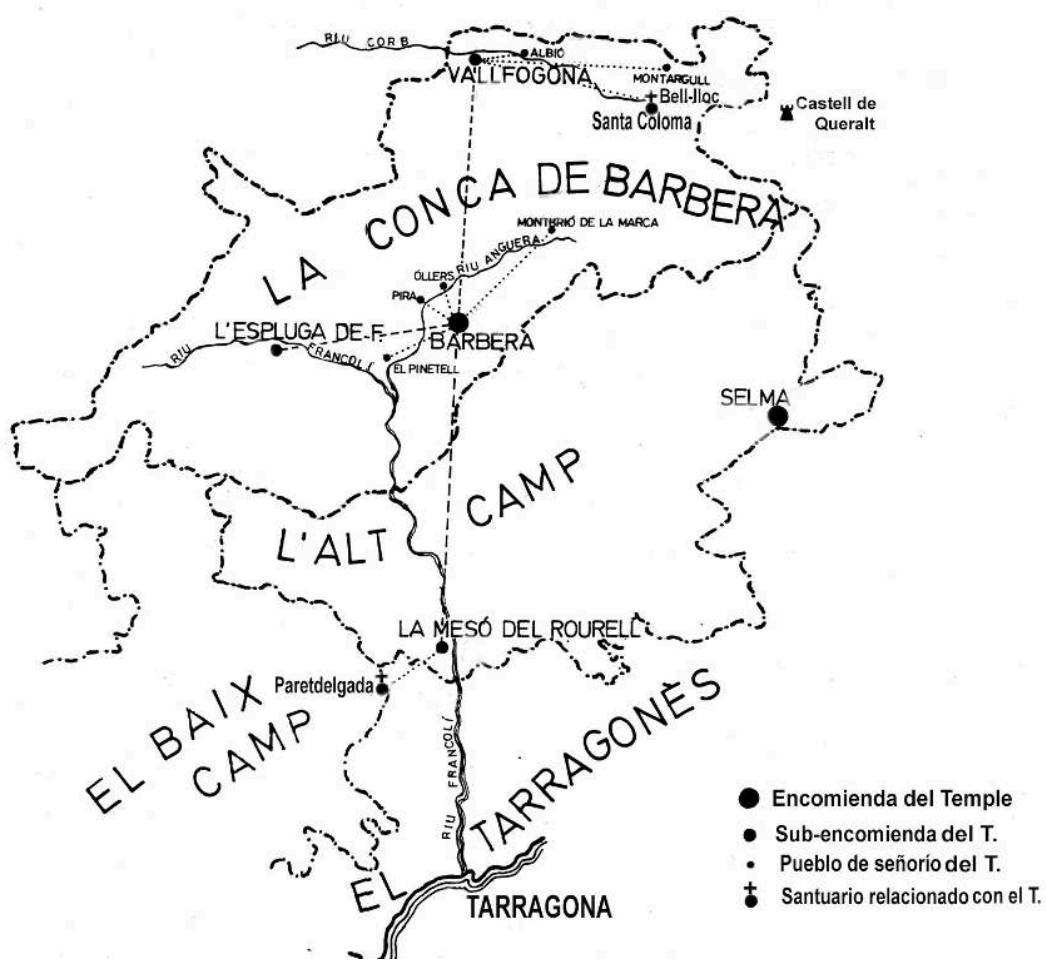

Fig. 2 - Encomienda de Barberà y sus dependencias.

Dibujo, Joan Fuguet.

Conca de Barberà constituía un territorio de gran valor estratégico en la retaguardia de la frontera. Es esperable que la encomienda que se asentó en el castillo de Barberà fuera una de las más importantes del Temple del Principado. Los preceptores y benefactores de la encomienda de Barberà y sus sub-encomiendas $\because$ Vallfogona, el Rourell y la Espluga de Francolí $\Leftrightarrow$ pertenecieron a la nobleza de la zona, principalmente con los Queralt-Timor, los Su, los Oluja y los Cervera-Torroja. Por otra parte, es obligado relacionar la consolidación de este territorio templario con la figura del Maestre Provincial y después Gran Maestre, Arnau de Torroja ${ }^{9}$, emparentado, además, con estos linajes.

De los Gurb'10 a los Queralt

Los orígenes del linaje Queralt ${ }^{11}$ se remontan a los Gurb, una familia cuyos antecedentes se encuentran en la conquista de la zona de Santa Coloma (Baixa Segarra y Conca de Barberà, en la Catalunya Nova). Los Gurb tenían importantes propiedades territoriales en la plana de Vic (Osona, Barcelona, Catalunya Nova) y se expandieron en tiempos de los condes catalanes por las tierras de la Marca. Una vez ampliado el patrimonio en el territorio de Gurb, emprendieron tareas de repoblación y aprissio por los condes catalanes en las nuevas tierras fronterizas: en los términos de Queralt, Figuerola, Rauric, Montargull (en las comarcas del Anoia, la Segarra y la Conca de Barberà).

Sendred de Gurb (fines del siglo X) fue un personaje muy vinculado a los condes de Barcelona y probablemente el primero de la familia que poseyó el castillo de Queralt (en Bellprat, Anoia), no sabemos si por compra o por usurpación, pero no fue hasta la cuarta generación, con su nieto Guillem Bernat, que los Gurb adoptaron el nombre Queralt $^{12}$. Uno de sus hijos segundones fue Berenguer Guillem de Queralt, quien recibió 
de su padre los castillos de Santa Coloma y Figuerola en alodio, es decir, en plena propiedad $^{13}$.

11 Con Berenguer Guillem comienza una rama secundaria de los Gurb-Queralt que poseyó un importante patrimonio en la zona de Santa Coloma. La rama principal empezó a decaer a causa de deudas, que originaron ventas y alienaciones, al tiempo que desmembraba sus posesiones en la zona de la Catalunya Nova y centraba su poder en la zona de Vic.

Berenguer Guillem figura entre los nobles de la Assemblea de Pau i Treva (Paz y Tregua de Dios) de 1134 en la que Ramon Berenguer IV, junto con el arzobispo Oleguer de Tarragona y otros magnates, concedía protección a la orden del Temple y acordaban las condiciones de su establecimiento en el país ${ }^{14}$.

Su hijo, Pere I de Queralt, fue un personaje notable ${ }^{15}$ que ayudó al conde-príncipe Ramon Berenguer IV en la conquista del Camp de Tarragona y las montañas de Prades ${ }^{16}$. Pere I poseía muchos castillos y territorios en la zona e intervino en muchos hechos importantes junto a los condes catalanes. En 1157 peregrinó a Jerusalén ${ }^{17}$ y diez años más tarde hizo testamento y se retiró al monasterio de Poblet donde profesó como monje y seguramente allí murió poco después. La figura de este personaje marca una constante en los nobles de su familia: la profesión de las armas, el servicio a los condes / reyes y la vocación religiosa.

El testamento de Pere I de Queralt dictado antes de profesar dejó como herederos a sus cuatro nepoti, Gombau de Oluja, Guillem de Timor, Ramon de Timor y Pere de Banyeres. El más favorecido fue Gombau de Oluja, a quien además de otros territorios le correspondieron los castillos de Queralt y Santa Coloma (este en alodio) y los de Rauric y Montclar, entre otros ${ }^{18}$. También heredó ciertos derechos que Pere I tenía en Conesa y en la Espluga de Francolí.

Gombau y Ermengarda de Oluja y las sub-encomiendas de Vallfogona y la Mesó del Rourell

El personaje de Gombau de Oluja y su esposa Ermergarda resultan interesantes para la historia del Temple de la encomienda de Barberà, así como la familia Su (también apelados Mont o Montargull), emparentados con ellos.

Ambas familias se habían establecido desde el siglo XII en la Conca de Barberà y la baja Segarra (en la Catalunya Nova), y controlaban la mayor parte de los castillos: los primeros eran señores de Vallfogona y los segundos tenían diversos derechos en Montargull y Albió, algunos compartidos con los Oluja. Desde el inicio de la conquista de la Conca de Barberà, en el siglo XII, Gombau de Oluja aparece como uno de los magnates de la zona ${ }^{19}$.

En virtud del testamento de Pere I de Queralt (1167), Gombau se convertía en uno de los nobles más poderosos de la Conca de Barberà. Sin embargo, el testamento conllevaba aceptar la herencia de las deudas del Queralt, unas deudas importantes reclamadas por los acreedores, quienes inmediatamente movieron causas contra Poblet, que tuvo que zanjar el rey Alfonso el Trovador. Esta situación llevó a Gombau en 1196 a empeñar al Temple el castillo y villa de Santa Coloma, junto con Savallà, Llorac (Conca de Barberà) y les Oluges (la Segarra), de modo que los citados lugares fueron propiedad de la Orden desde 1196 hasta 1213. El Temple ayudó a Gombau a sostener sus necesidades económicas y, a cambio, éste se convirtió en uno de los principales benefactores de la encomienda de Barberà (Fig. 3). 


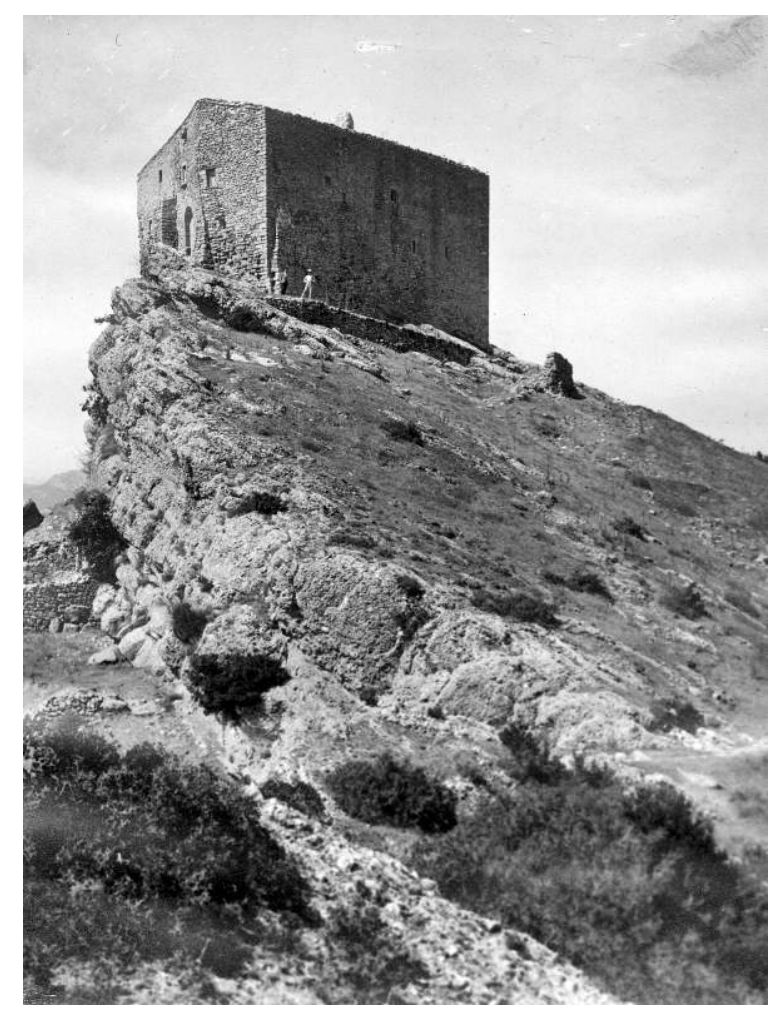

Fig. 3 - Castillo de Queralt en 1918 (Bellprat, Anoia -Barcelona-)

Fotografía Català Pic.

Gombau se libró al Temple en 1191 en cuerpo y alma juntamente con su esposa Ermengarda y cedió a la orden el castillo de Vallfogona (Conca de Barberà) con sus habitantes, casas tierras y todas sus pertenencias ${ }^{20}$. Las donaciones al Temple de Gombau deben entenderse dentro de la práctica habitual de donaciones retribuidas entre la Orden y los donantes ${ }^{21}$. Además de ayuda material, el Temple le proporcionó probablemente también salvaguarda personal dada la situación creada por la acusación que pesaba sobre él de incitar al asesinato del arzobispo de Tarragona ${ }^{22}$. Es significativo que después de los sucesos de Tarragona la actividad de Gombau se documente exclusivamente en la Conca de Barberà. A partir de la donación de los Oluja - Gombau y Ermengarda -, la casa de Barberà estableció una sub-encomienda en Vallfogona ${ }^{23}$.

Gombau desaparece de la documentación a finales del siglo XII y su esposa, Ermengarda, que le sobrevivió, residió en la casa del Rourell, una sub-encomienda de Barberà, en tierras del Camp de Tarragona ${ }^{24}$ que se formó a partir de la donación que el 1160 realizó Berenguer de Molnells del antiguo más de Bellestar al ingresar en el Temple. Aunque tradicionalmente se ha hablado de la encomienda del Rourell, las afrontaciones de dicho mas no corresponden a esta localidad sino al cercano pueblo de la Masó25; por lo tanto resulta más exacto hablar de la sub-encomienda de "la Mesó del Rourell" 26 .

La casa de la Mesó del Rourell estuvo regentada entre 1162 y 1180 / 1181 desde Barberà. Entre 1181 y 1187 se organizó la sub-encomienda bajo las directrices de la casa madre y es entonces cuando se documenta el primer preceptor. En el periodo de 1187 a 1197 hay noticia de otros dos comendadores, Guillem de Paratge y Pere de Aguda; fue durante el gobierno de este último cuando se produjeron las donaciones al Temple de Gombau y Ermengarda de Oluja (diciembre de 1196), de Titborga de Santa Coloma (enero 1197) y 
de Berenguer Duran (diciembre 1197). Pere de Aguda cesó como comendador de Barberà en mayo de $1198^{27}$. En agosto del mismo año, se repite la donación de 1197 a la casa del Rourell de Berenguer Duran, ahora en manos de Ermengarda de Oluja, quien la recibe como preceptorix de dicha casa.

El hecho de que en el documento aparezca una mujer ${ }^{28}$ como preceptorix ${ }^{29}$ regentando una casa del Temple supone una peculiaridad bastante insólita en la organización templaria que induce $\operatorname{Sans}^{30}$ a afirmar que en el Rourell existió una encomienda templaria mixta, aunque más tarde, sin justificación alguna, cambió la expresión "preceptoria mixta" por "encomienda mixta de donados"31.

Ermengarda y su esposo Gombau habían sido admitidos en el Temple como frater et soror. Aunque la admisión conjunta ya supone que se trata de fratri coniugati, es decir, donados ${ }^{32}$, la terminología utilizada en los instrumentos de donación es ambigua puesto que, soror, donata e incluso consoror son utilizados indistintamente en una misma persona ${ }^{33}$. Hay que tener también en cuenta que la donación de 1198 de Berenguer Duran a la casa del Rourell viene precedida por una de diciembre de $1197^{34}$ en la que se dona en cuerpo y alma en manos del comendador fra Pere de Aguda y de otros fratres de la casa del Rourell y pide que hagan con él lo mismo que con otros donados que viven en la misma casa ${ }^{35}$.

Aunque resulta casi imposible saber el grado de afiliación al Temple de los donados o fratres y sorores de la casa del Rourell, quizá pueda resultar indicativo observar que la donación de Gombau y Ermessenda de Oluja, la de Titborgis, hija de Berenguer de Santa Coloma (pariente de los Queralt-Timor) y la primera de 1196 de Berenguer Duran estuvieron presididas por el comendador de Barberà, mientras que en la segunda de Berenguer Duran, de 1198, solamente aparece Ermengarda y otros fratres. Que la preceptorix que regía la casa del Rourell fuera Ermengarda puede ser debido a que Gombau ya había muerto en aquella fecha (diciembre de 1198) y su viuda era la persona de más categoría social de la comunidad ${ }^{36}$. En el momento de la donación, la casa madre de Barberà era sede vacante de comendador, de manera que otra persona había de asumir la representación a efectos notariales (Fig. 4).

Resulta difícil establecer el estatus de los miembros de la comunidad de la Mesó del Rourell ya que podría tratarse o bien como una comunidad mixta de fratres y sorores con votos, o bien como una comunidad de frailes con donados que vivían en la misma casa o bien como una comunidad de donados; los diferentes tipos de afiliación a la Orden y la confusa terminología que ello conlleva ${ }^{37}$ no permite saber exactamente la posición de la preceptorix del Rourell. El comendador de Barberà, Pere de Aguda volvió a regir conjuntamente esta casa en 1199; por lo tanto, la dirección de Ermengarda no debió durar más de dos años. Más tarde, en 1204, fue comendador del Rourell Guillem de Mont, emparentado con los Oluja, que había sido anteriormente comendador de Barberà $^{38}$. 


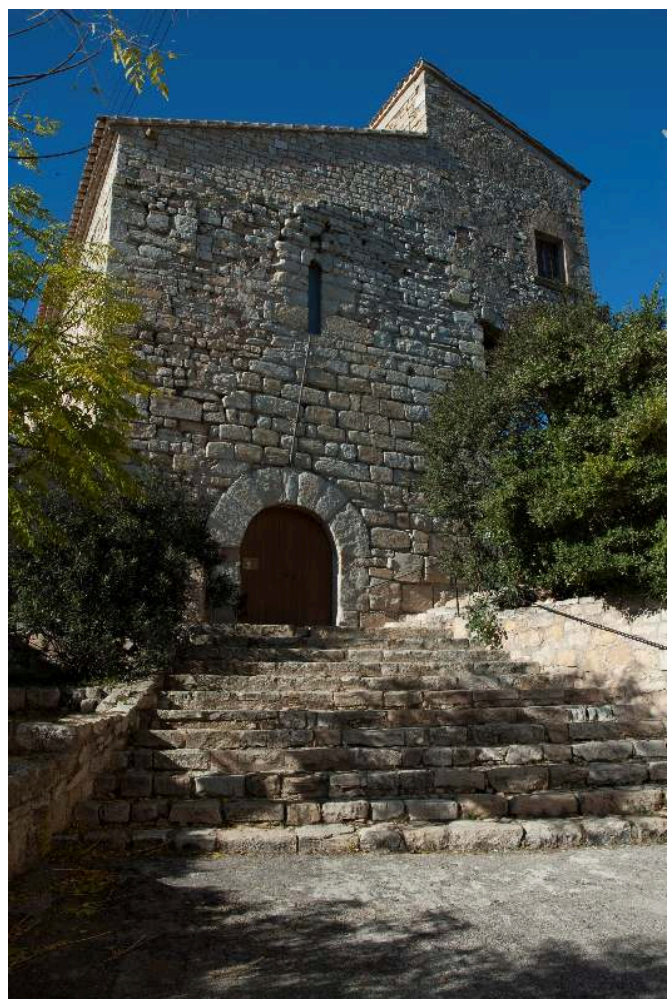

Fig. 4 - Barberà, puerta principal del castillo (Barberà de la Conca, Conca de Barberà -Tarragona-).

Fotografía Joan Fuguet.

La encomienda del Rourell fue siempre de poca importancia. Era de carácter rural y sus tierras las cultivaban directamente los frailes, ayudados por esclavos, una situación bastante atípica en las encomiendas del Temple ${ }^{39}$. Las dificultades de la Orden por conservar sus dominios en el Camp de Tarragona los llevó a alienar la encomienda el año 1248. Aparentemente no se conserva nada de su sede, tal vez la tipología urbana y de la pequeña población es heredera de ella. Sólo conocemos por los documentos que tenía una pequeña iglesia y un cementerio ${ }^{40}$. Los edificios de la sub-encomienda constituían un pequeño núcleo, eminentemente agrícola, que debió conservarse con pocas variaciones hasta fines del siglo XVIII. Ello se deduce a partir del escaso número de habitantes "sis focs" que el pueblo de la Masó mantenía en el siglo XVI ${ }^{41}$.

La categoría social de Ermengarda y Titborga -desconocemos la del resto de la comunidad-parece avenirse mal con un convento humilde de este tipo cuyos miembros se dedicaban al cultivo de las tierras. Por este motivo, Fuguet ${ }^{42}$ avanzó la hipótesis de que podía existir una comunidad mixta de donados de la casa del Rourell que habitasen el santuario de Paretdelgada. Paretdelgada es un santuario dedicado a la Virgen, situado a $5 \mathrm{Km}$ de la encomienda, en término de la Selva del Camp y no existe ninguna documentación ${ }^{43}$ que permita probar esta hipótesis. Sin embargo, la literatura sobre el lugar recoge la tradición ${ }^{44}$ de la existencia allí de un establecimiento dependiente de la casa del Temple de Barberà. El historiador local mosén Piée ${ }^{45}$, afirma que el santuario fue habitado y cuidado por donados desde su fundación, a fines del siglo XII; el problema radica en saber la identidad y función de esta comunidad, pero dada la situación del santuario en el camino de Tarragona a Lleida bien podía ser la del culto del templo y la de acoger a peregrinos y viajeros. 

hospicio. La cronología y la arquitectura del templo coincide en el tiempo - fines del siglo XII- ${ }^{46}$ con la de la supuesta comunidad de donados, y su arquitectura es la misma que la de muchas iglesias con arcos diafragma de territorios templarios ${ }^{47}$. Otro elemento a tener en cuenta para justificar esta hipótesis es el hecho de que el Pavorde de la seo tarraconense fuera el señor de la Selva del Camp, ya que la catedral de Tarragona acabó adueñándose de las antiguas propiedades de la Mesó del Rourell.

Fue señor de Queralt y de Santa Coloma y se casó con Berenguera de Cervelló, hija de
Ramon Alemany de Cervelló, otro noble catalán con el que había coincidido en la
conquista de Mallorca (1229) junto a Jaume I. Pere II Intervino también en la conquista
de Valencia y fue uno de los caballeros que firmaron los pactos de rendición de la
ciudad el $1238^{49}$ (Fig. 5).

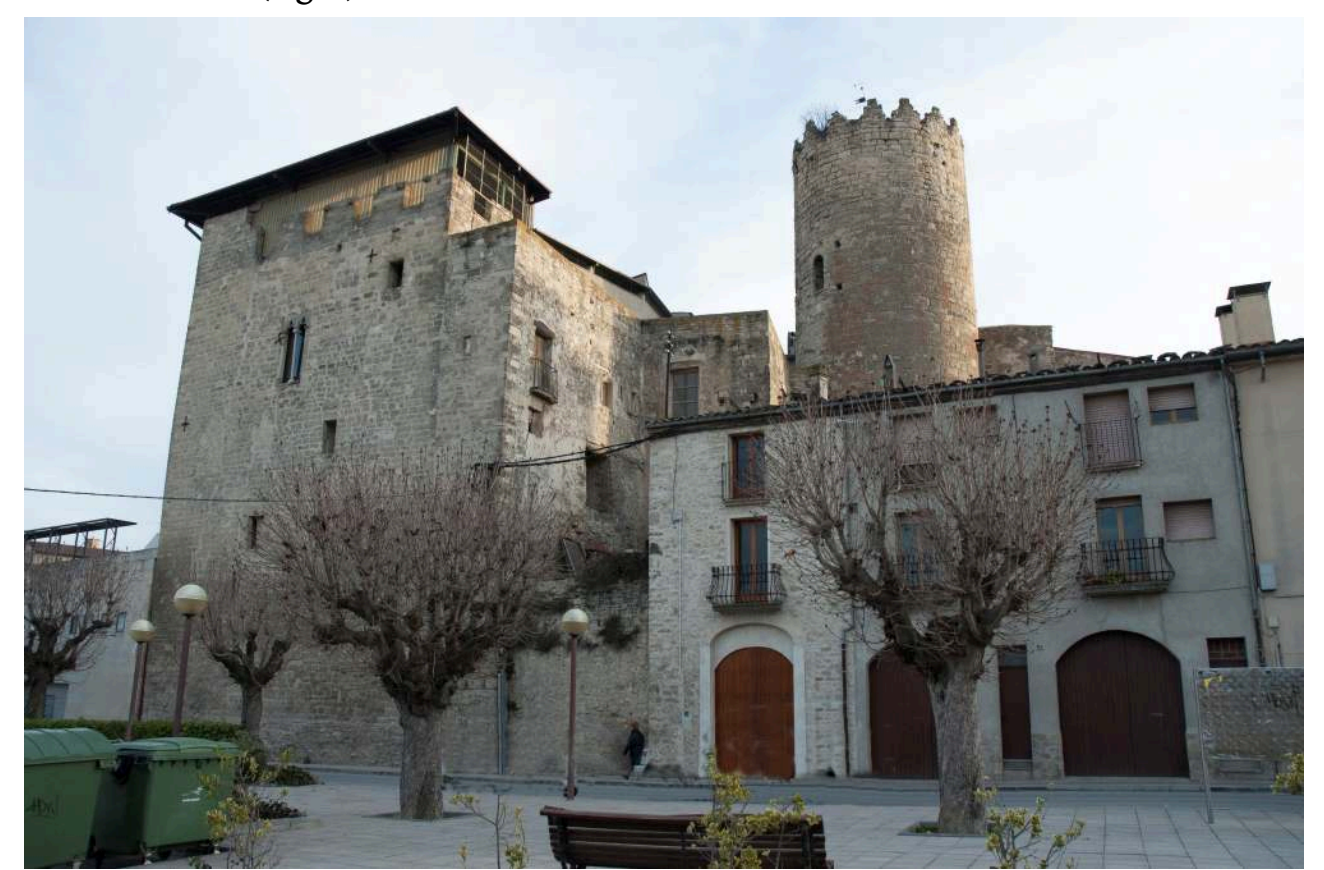

Fig. 5 - Santa Coloma de Queralt. Castillo, fachada lateral (Santa Coloma de Queralt, Conca de Barberà -Tarragona-).

Fotografía Joan Fuguet.

Dispuso, como señor de Santa Coloma, numerosas ordenanzas de la villa, antes y después de su profesión en el Temple. En 1256 hizo testamento y legó el lugar del Codony al monasterio de Poblet, confirmó la donación de Montargull que anteriormente había hecho a los templarios y cedió a su hijo Pere III, el continuador de 
la estirpe y de la baronía de Queralt el resto de sus posesiones, haciendo constar que si éste moría sin descendencia lo habían de sustituir sus hermanos. Sin embargo, los castillos de Santa Coloma, Rauric y Figuerola debían regresar al Temple, si estos no tenían descendencia ${ }^{50}$.

Cuando realizó el testamento, Pere II ya era viudo ${ }^{51}$ e ingresó en la orden del Temple probablemente en 1257. No sabemos qué otras donaciones además de Montargull acompañaron su profesión. Documentación referida a transacciones y negocios de Pere II lo citan como fra a partir de 1260, indicio de su ingreso en la orden el Temple ${ }^{52}$. Sin embargo, continua en los documentos como señor temporal de Santa Coloma de Queralt y sus posesiones ${ }^{53}$.

No se conserva el documento de la profesión de Pere II de Queralt en la Orden, pero está documentado que a partir de 1260 desempeñó en ella cargos de gran importancia: en 1260-1262 fue comendador de Monzón; entre 1262-1264 comendador de Miravet, entre 1265-1267, de Gardeny, y Lugarteniente ${ }^{54}$ del Maestre Provincial en 1261, 1262 y 1266. Acudió a la campaña de Murcia (1265-1266) junto a Jaime I como representante del Maestre Provincial ${ }^{55}$.

Sorprende la carrera meteórica de Pere $\mathrm{II}^{56}$ : apenas ingresado en el Temple, y ya probablemente de mediana edad, rigió las encomiendas más importantes de la provincia catalano-aragonesa y fue Lugarteniente del Maestre. Es posible que su carrera en la Orden fuera originada por su anterior carrera militar en las conquistas de la Corona y su buena relación con Jaime I. Pere II de Queralt fue un noble militar catalán qua aportó al Temple su experiencia en la lucha contra los musulmanes, una característica que compartida con otros nobles templarios catalanes, como anteriormente Arnau de Torroja ${ }^{57}$, Guillem de Mont-redon ${ }^{58}$ y sus contemporáneos los Anglesola, los Castellnou, los Rocabertí59, con los que la familia Queralt estableció relaciones de parentesco. El ingreso en la Orden les proporcionaba beneficios materiales y espirituales.

Como señor de Santa Coloma, Pere II intervino también en obras arquitectónicas importantes en la villa: la remodelación del castillo-palacio y la construcción de la portada del santuario de Santa Maria de Bell-lloc (Fig. 6).

El castillo es un edificio ${ }^{60}$ que tiene su origen probablemente en una torre del siglo XI, que un siglo más tarde fue sustituida por la actual. Una remodelación importante se debe al siglo XIII, en tiempos de Pere III, cuando se construyó una gran sala gótica rectangular con arcos diafragma de perfil apuntado que arrancaban de semi-columnas adosadas a los muros laterales. Las remodelaciones posteriores de que ha sido objeto han desfigurado parcialmente su apariencia primitiva, pero afortunadamente se ha conservado el primer tramo de la gran sala rectangular. Las semi-columnas que soportan los arcos de la sala gótica del castillo de Santa Coloma son de la misma factura que las que soportan las bóvedas de la iglesia de Santa Maria de Bell-lloc y también de las de la sala del castillo del Temple de Vallfogona ${ }^{61}$; las tres obras son contemporáneas y corresponden a la segunda mitad del siglo XIII (Fig. 7). 


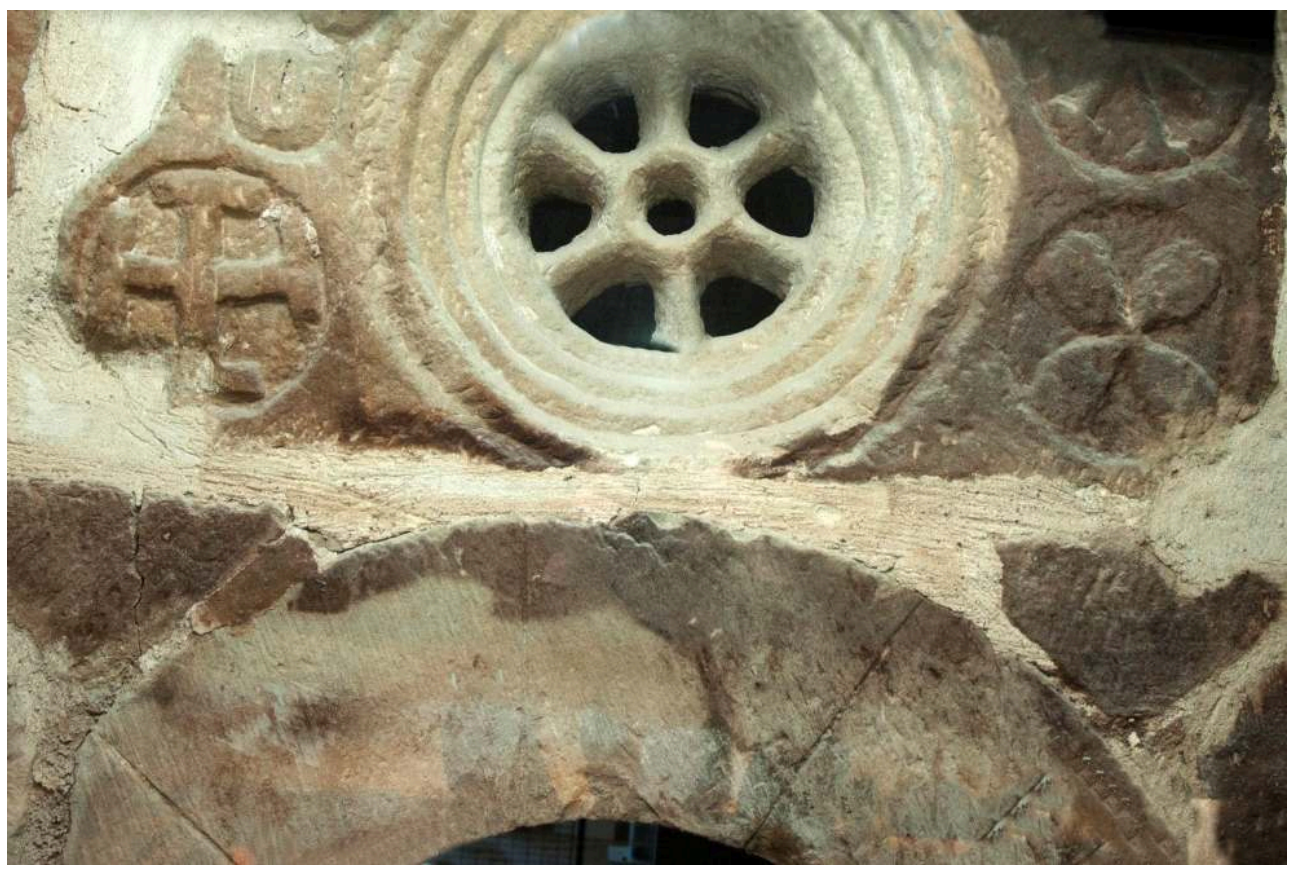

Fig. 6 - Santa Coloma de Queralt. Castillo, detalle heráldico en la sala principal (Santa Coloma de Queralt, Conca de Barberà - Tarragona).

Fotografía Joan Fuguet.

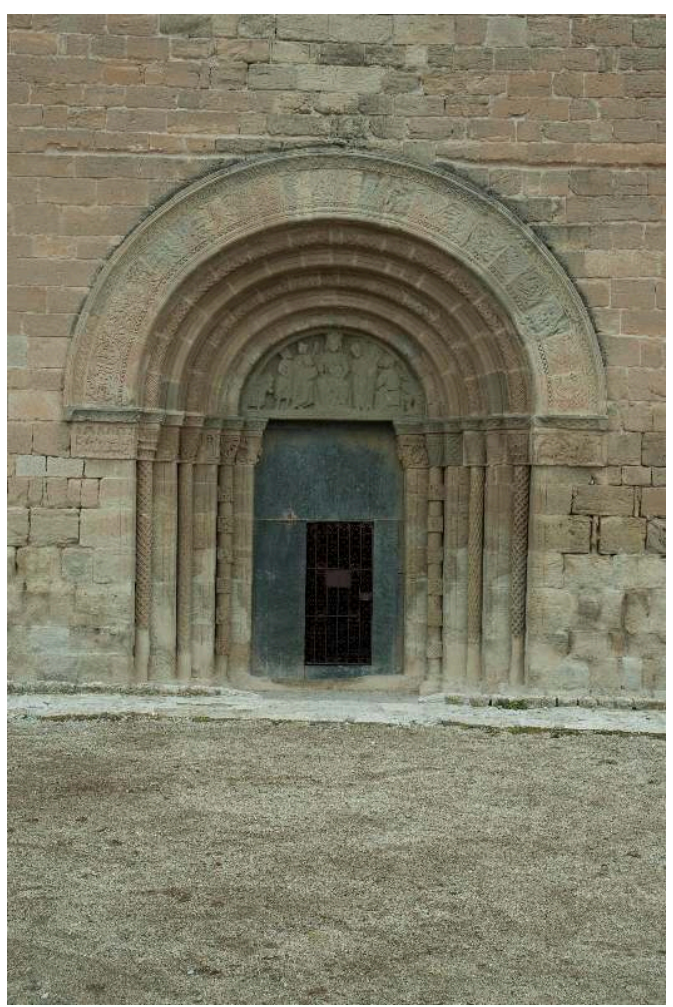

Fig. 7 - Santa Coloma de Queralt. Santuario de Bell-Iloc. Portal principal (Santa Coloma de Queralt, Conca de Barberà -Tarragona-).

Fotografía Joan Fuguet.

Un detalle interesante de la gran sala de Santa Coloma es el elemento decorativo que aparece en una de las ventanas triforas de la galería: una cruz potenzada inscrita en un círculo y otra cruz patente también inscrita en un círculo. Sin embargo, no parece ser 
solo un elemento puramente decorativo, ya que una cruz patente de las mismas características decora el exterior de la portezuela del lado norte de la iglesia de Bell$1 l^{6}{ }^{62}$, un edificio también relacionado con Pere II de Queralt, y es el mismo motivo que aparece en uno de los capiteles de la galería del castillo templario de Corbera d'Ebre ${ }^{63}$.

El santuario de Santa María de Bell-lloc, situado a un km de la villa de Santa Coloma ha sido objeto de diferentes estudios desde el punto de vista histórico y artístico ${ }^{64}$. Los documentos más antiguos datan de 1260 y 1270 y se refieren a una comunidad de donados que cuidaban el santuario ${ }^{65}$. Esta comunidad tenía su propio estatuto y era regida por un mayoral elegido por la comunidad con el consentimiento del señor de Queralt. Había hombres y mujeres donados y frailes, que recibían el hábito. En 1170 los donados decidieron transferir parte de sus privilegios al párroco de Santa Coloma, hecho que refleja una decadencia de la institución que se vio aumentada cuando en 1307 cedieron el santuario a la Orden de la Merced ${ }^{66}$. Anteriormente, los Queralt se habían enterrado en los cercanos monasterios cistercienses de Poblet y Santes Creus ${ }^{67}$ mientras que Bell-lloc se convirtió en mausoleo de la familia, probablemente a partir de Pere II ${ }^{68}$ y desde fines del siglo XIII los señores de Queralt eligieron sepultura de manera permanente en Bell-lloc.

La gran puerta monumental del santuario se ha datado a mediados del siglo XIII ${ }^{69}$, en tiempos de Pere II, y constituye un importante conjunto artístico cargado de simbología. En primer lugar, muestra elementos heráldicos: la cruz ${ }^{70}$, el escudo de los Queralt - un león rampante coronado -; un ciervo, posiblemente el de la esposa de Pere II, Berenguera de Cervelló y unas fajas vibradas del linaje Anglesola. En el lado izquierdo del friso hay una escena en la que aparece un personaje arrodillado frente a un fraile la cual se ha interpretado como la obligación de orar y proteger los peregrinos propia de las órdenes militares ${ }^{71}$; sin embargo, es más plausible que aluda a la ceremonia de la imposición del hábito a los donados de la casa, puesto que la representación escultórica coincide con el hábito descrito por Segura ${ }^{72}$ (Fig. 8).

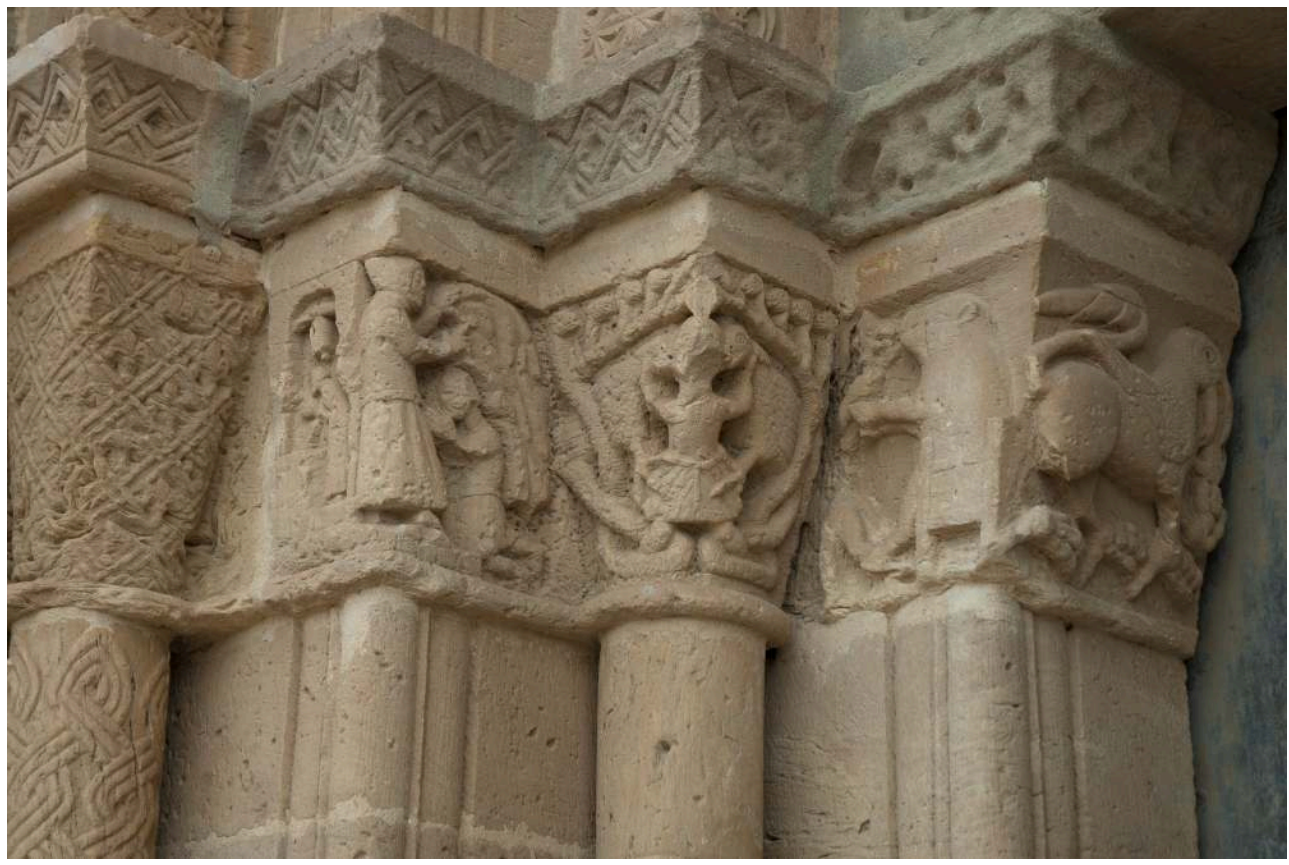

Fig. 8 - Santa Coloma de Queralt. Santuario de Bell-Iloc. Friso de la arquivolta en que se representa la imposición del hábito a los donados (Santa Coloma de Queralt, Conca de Barberà -Tarragona).

Fotografía Joan Fuguet. 
Además del león rampante, símbolo heráldico de los Queralt, aparece en otros relieves un caballero luchando con este animal. Esta escena, que se muestra en la puerta y en la clave de la bóveda de la capilla del panteón de Pere IV y Francesca de Castellnou (siglo XIV), se ha relacionado con una hazaña de Pere II de Queralt, según la cual, el caballero, luchando valientemente, fue hecho prisionero en una batalla; cuando sus enemigos conocieron su identidad, quisieron poner a prueba su valor y le prometieron la libertad si luchaba contra un terrible león, al que, naturalmente, venció. La hazaña le valió el sobrenombre "Cor de Roure" (Corazón de Roble) (Fig. 9).

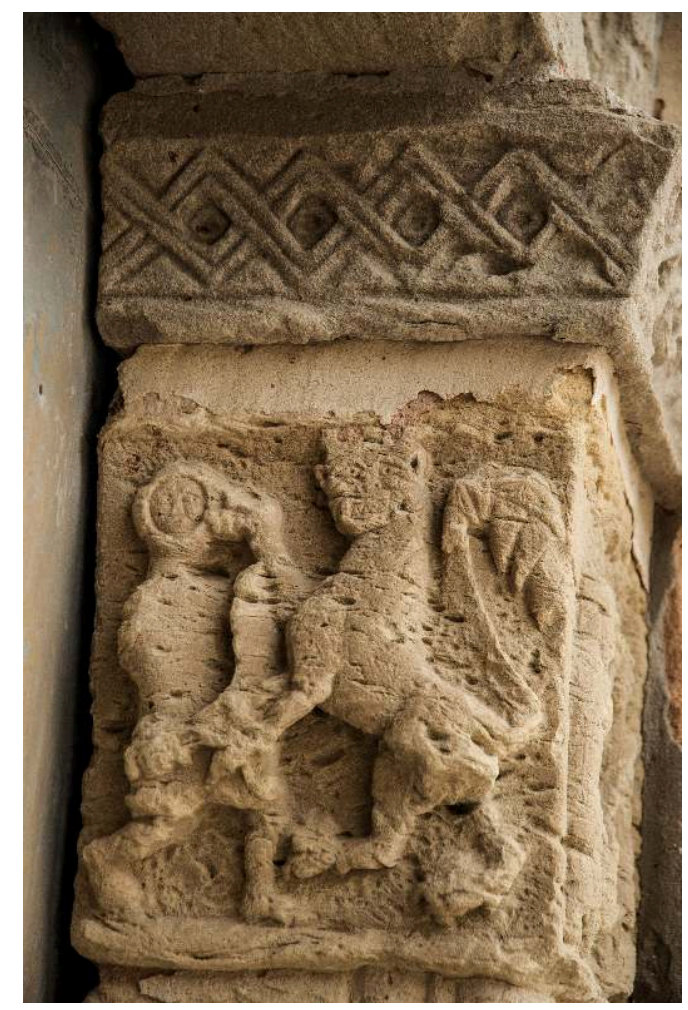

Fig. 9 - Santa Coloma de Queralt. Santuario de Bell-Iloc. Capitel de la arquivolta en que se representa la leyenda del "Cor de Roure" (Santa Coloma de Queralt, Conca de Barberà -Tarragona).

Fotografía Joan Fuguet.

Desconocemos la antigüedad de esta leyenda, fue recogida en el siglo XVIII ${ }^{73}$, pero que debía de haberse transmitido oralmente; prueba de ello es que dio lugar a una obra de teatro romántico en el siglo $\mathrm{XIX}^{74}$. El significado de la escena parece aludir a la lucha entre el bien y el mal ${ }^{75}$, que, en el contexto guerrero de Pere de Queralt, puede tener el significado añadido de la lucha de los cristianos cruzados contra el Islam ${ }^{76}$.

No existen motivos para afirmar que Bell-lloc fuera un establecimiento templario, pero su historia y su arquitectura muestran que existió una relación directa entre el santuario y el señor de Queralt, Pere II, y, por extensión, con la Orden. Por otra parte, las características comunes entre Bell-lloc, el castillo de Santa Coloma y otros edificios contemporáneos de establecimientos del Temple - Corbera [de Ebro], Vallfogona permiten situarlo dentro de la categoría de obras realizadas bajo los auspicios de un personaje directamente relacionado con la Orden. El "dictamen" previo a declarar el santuario monumento histórico-artístico lo consideraba una construcción templaria ${ }^{77}$. 

y sus herederos, la rama principal del linaje, adoptaron el nombre Queralt mientras que sus hermanos, Jaume y Arnau, adoptaron el de Timor. Ambos desempeñaron también cargos importantes en la Orden del Temple: Jaume fue comendador de Gardeny y Barberà y Lugarteniente del Maestre Provincial, y Arnau lo fue de Monzón, Gardeny y Huesca y también Lugarteniente del Maestre ${ }^{78}$ (Fig. 10).

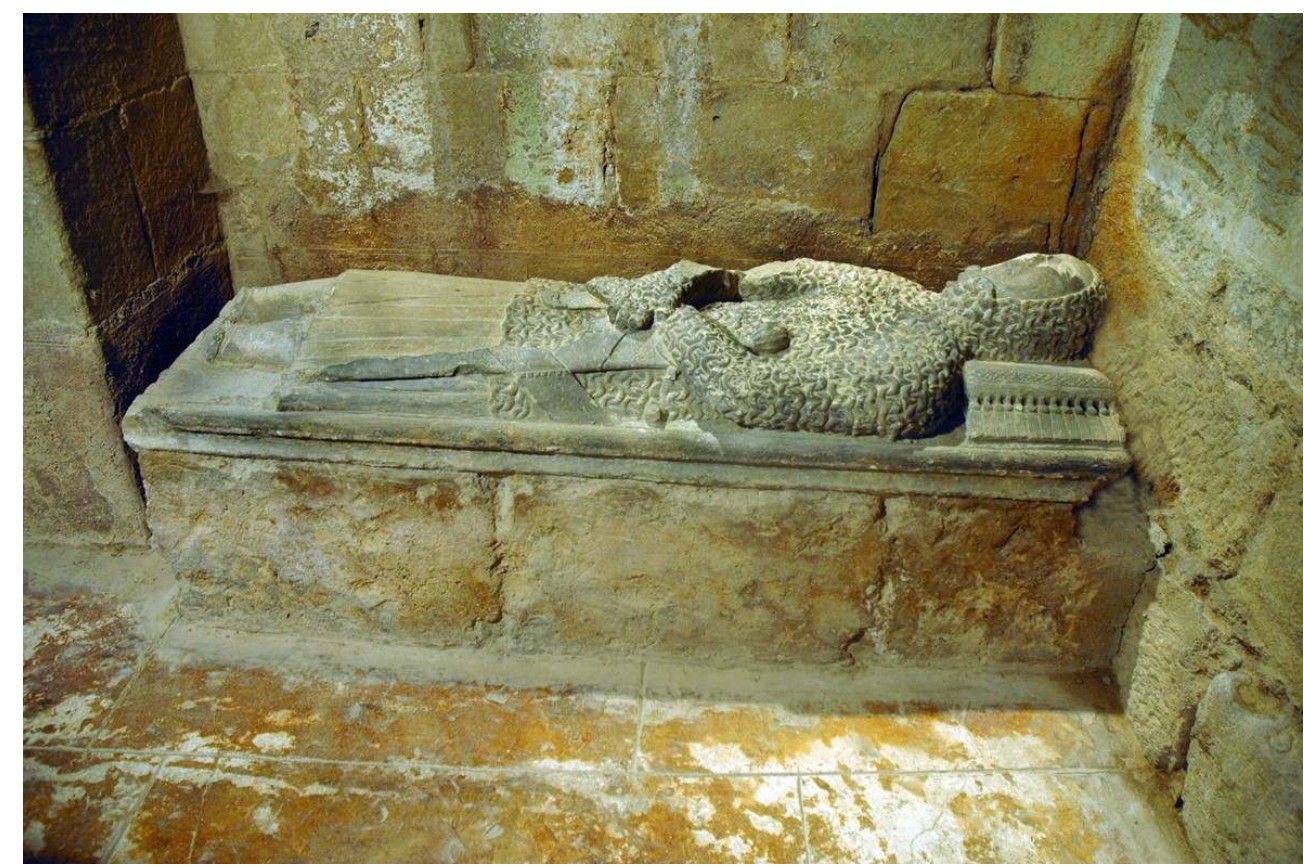

Fig. 10 - Santa Coloma de Queralt. Santuario de Bell-Iloc. Tapa de sepulcro de un caballero de Queralt, presuntamente Pere II "Cor de Roure". (Adquirido a un anticuario, desde 1918 se encuentra en el monasterio cisterciense de Fontfreda, Rosselló -Francia).

Fotografía Joan Fuguet.

En la historia del Temple catalán hay otros personajes con el apellido Timor. Aunque no podemos establecer el parentesco entre ellos y los Queralt, sí que podemos afirmar que pertenecen a una rama lateral del mismo linaje originario. Establecer el parentesco de los Queralt resulta relativamente fácil puesto que, como barones, siguieron una línea patrilineal clara. No ocurre lo mismo con los Timor cuyas relaciones de parentesco no hemos podido establecer; solamente conocemos que los descendientes de esta familia señorearon territorios en la zona, a veces compartidos con los Queralt y que su personaje más conocido - Dalmau de Timor - está relacionado con la encomienda de Barberà.

Dalmau de Timor fue en 1300 jefe de los turcoples ${ }^{79}$ en Chipre donde alcanzó un gran prestigio. Fue luego comendador de Barberà de $1305 \mathrm{a} 1307^{80}$. Cuando los templarios de la corona catalano-aragonesa, asediados por las tropas de Jaime II se replegaron en sus castillos, Dalmau marchó de Barberà a Monzón, una fortaleza más segura. Allí tuvo enfrentamientos con el comendador, Berenguer de Bellvís, y organizó algaradas en los pueblos vecinos ${ }^{81}$. Era personaje muy apreciado por Jaime II $^{82}$ quien escribió al Gran Maestre, Jacques de Molay proponiendo que lo nombrara Maestre Provincial ${ }^{83}$, cargo que finalmente Molay adjudicó a Ximen de Lenda. Después del proceso Dalmau no se retiró a ningún convento sino que continuó con una activa vida militar dentro de la familiaritas del Rey y participó en la conquista de Cerdeña ${ }^{84}$. 

continuaron luchando en las guerras de los reyes: en la frustrada cruzada de Jaime I a Tierra Santa, en la conquista de Cerdeña, en las campañas de Almería y del norte de África... principalmente por vía matrimonial, con las que compartió la participación en las campañas de los reyes. Seguir todas las relaciones tejidas con estas familias resultaría excesivo y no exento de gran dificultad. Aquí nos hemos limitado a señalar los parentescos más directos algunos de cuyos miembros también profesaron en el Temple.

51 Pere III de Queralt y de Cervelló, hijo de Pere II participó como caballero principal en las campañas del rey Pere II. Intervino en las Vísperas Sicilianas ${ }^{85}$. Se casó con Margelina de Anglesola.

52 La familia Anglesola era una de las principales familias nobles asentada en las tierras de Lleida que favorecieron las encomiendas templarias del Segre, - Barbens, Corbins y Gardeny ${ }^{86}$. El padre de Margelina era Guillem III de Anglesola, templario, que profesó en el Temple con consentimiento de su mujer. Según Miret $^{87}$ fue comendador de Gardeny en 1247 y de Horta en 1255. Es probable que sea el mismo que, según Forey ${ }^{88}$, fue comendador de Barberà en 1246 y 1258-1260; de Gardeny, en 1247; y de Corbins 1261. Tenemos noticias de Guillem por una denuncia al Maestre del Temple, entonces Arnau de Castellnou, sobre una agresión que había realizado un hijo del templario Guillem de Anglesola, con el consentimiento de su padre, contra Huguet de Cervellós ${ }^{89}$.

Guillem III fue el hermano de Geralda de Anglesola, esposa de Simó de Palau ${ }^{90}$, quien, sin descendencia masculina, dejó el castillo de la Espluga de Francolí al Temple y este estableció allí una sub-encomienda que dependía de la casa de Barberà. El testamento llevó a Gueralda y después a su hija Sibila a pleitear con el Temple ${ }^{91}$. Guillem III de Anglesola, se casó en primeras nupcias con Constanza de Alagón, hija de Blasco de Alagón, gran colaborador de las campañas de Jaime I en el reino de Valencia, señor de Culla. Su hijo vendió Culla a los templarios para ampliar la encomienda de Peníscola ${ }^{92}$.

En 1307 ingresó en el Temple Ramon de Anglesola93 (que pertenecía a otra rama ${ }^{94}$ de los Anglesola) en la encomienda de Barberà, pero con la particularidad que la profesión se realizó en el convento de los franciscanos de Montblanc, al tiempo que se realizaba una asamblea de la Orden ${ }^{95}$. La pertenencia de Ramon a un linaje importante fue probablemente el motivo por el cual después del proceso recibió una pensión de 4000 sueldos barceloneses, como Dalmau de Timor o Berenguer de Bellvís, sin haber estado al frente de ninguna encomienda y de haber profesado en la Orden poco antes del proceso ${ }^{96}$.

Pere IV, hijo de Pere III de Queralt y de Margelina de Anglesola, participó en la campaña de Cerdeña. Intervino en las negociaciones con los templarios en el sitio de Miravet en 1308 y fue uno de los enviados por Jaume II al concilio de Viena del que realizó un exhaustivo resumen ${ }^{97}$. Se casó con Francesca de Castellnou ${ }^{98}$ que pertenecía a una familia noble del Rosselló que se mantuvo fiel a Pere II en la lucha con Jaume de

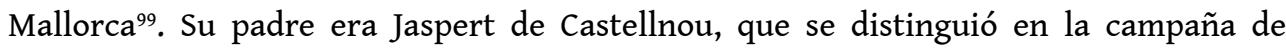


Granada y conquistó Ceuta ${ }^{100}$. Su tío abuelo, Arnau de Castellnou fue Maestre Provincial del Temple de 1267 a $1277^{101}$.

Según la genealogía establecida por P. Ponsic y seguida por P-V. Claverie, Francesca era hija de Jaspert V de Castellnou y su segunda esposa, Galceranda de Narbona ${ }^{102}$. Sin embargo, según A. de Fluvià ${ }^{103}$ Francesca era hija de un primer matrimonio de Jaspert con Alamanda de Rocabertí. Alamanda era hija del vizconde de Rocabertí y su primera esposa Ermesenda Desfar. Por lo tanto, sería hermanastra de Guillem y Dalmau de Rocabertí fruto del matrimonio de Dalmau con Guillema de Cervelló. Mas tarde los Queralt emparentaron con los Rocabertí mediante el matrimonio de Pere V de Queralt y Castellnou con otra Alamanda de Rocabertí, sobrina de la primera (Fig. 11).

Guillem de Rocabertí fue arzobispo de Tarragona y presidió el Concilio de Tarragona (1312) en que se absolvió a los templarios de la Corona de Aragón. Dalmau de Rocabertí estuvo al mando de la guarnición del Temple en la isla de Arwad, fue capturado y llevado prisionero a Egipto, donde permaneció hasta 1315. Una vez hubo regresado a Cataluña, se retiró al convento de Sant Martí en Girona ${ }^{104}$. La importancia del personaje se aprecia en el interés que desplegó el rey Jaume II hasta conseguir su liberación ${ }^{105} \mathrm{y}$ en el hecho de ser el miembro del Temple de la corona catalano-aragonesa que obtuvo la mayor pensión después de la abolición del Temple (8.000).

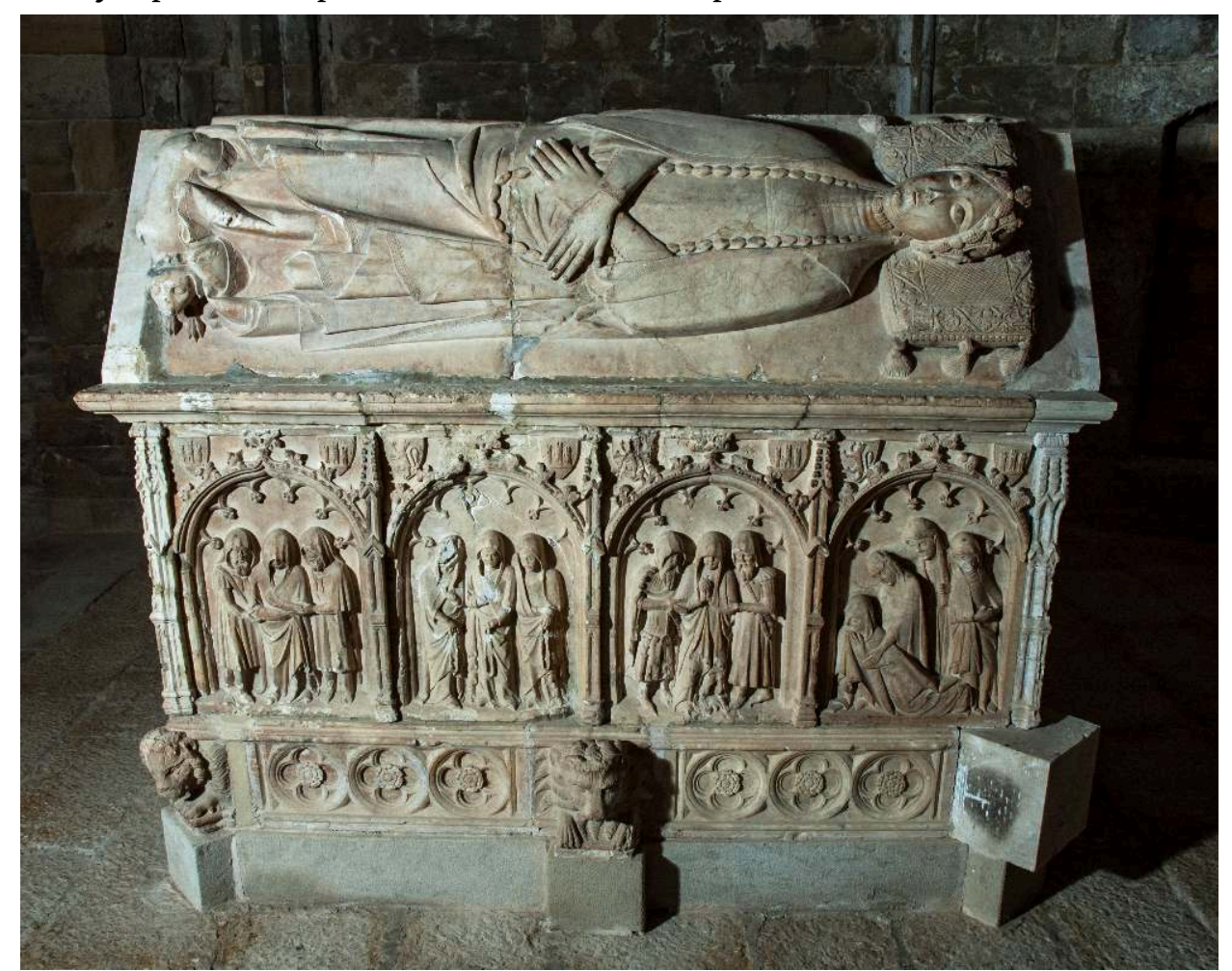

Fig. 11 - Santa Coloma de Queralt. Santuario de Bell-Iloc. Sepulcro doble de Pere IV de Queralt y Francesca de Castellnou. Lado correspondiente a Francesca donde se aprecia la heráldica de ambas casas. (Santa Coloma de Queralt, Conca de Barberà -Tarragona).

Fotografía Joan Fuguet.

\section{A manera de conclusión}

La trayectoria de la familia Queralt-Timor ejemplifica una relación de la nobleza medieval catalana con la orden del Temple, que, en parte, es compartida por otros linajes principales. 

campañas de la conquista cristiana. Esta situación es parecida a la de otros templarios catalanes, que alcanzaron grandes puestos en la Orden. Pere II de Queralt era ya de mediana edad y viudo cuando entró en la Orden; hay que recordar que el Temple no impedía que profesaran personajes casados si sus esposas daban el consentimiento, como el ya citado Guillem de Anglesola ${ }^{106}$.

61 La profesión - o donación - al Temple de los Oluja, parientes de los Queralt proporcionó a la Orden un señorío en el que instalaron una subencomienda. Sin embargo, no se registran donaciones de Pere a la casa de Barberà. Y así como algunos importantes templarios ${ }^{107}$ donaron todo su patrimonio a la Orden, el señor de Queralt así como el de Anglesola dejaron la mayor parte del patrimonio a sus hijos, que continuaron el linaje. Así, los Queralt mantuvieron su patrimonio e incluso recuperaron lugares que habían sido empeñados a la Orden; también Guillem III de Anglesola dejó el señorío de Culla a su hijo Guillem IV, quien lo vendió al Temple ${ }^{108}$. profesaron en el Temple no eran los herederos del patrimonio, Pere II de Queralt y Guillem III d'Anglesola rompen el esquema, ya que son los que conservan el señorío, que transmiten a sus hijos. excluyentes entre sí. Por una parte, un sentimiento religioso de cruzada y, por otra, la vocación guerrera de una aristocracia militar ocupada en la conquista de la Península.

El sentimiento religioso había conducido a algunos miembros de la nobleza a peregrinar a Jerusalén, pero más adelante, en pleno avance de la conquista cristiana, las elites guerreras encontrarán un cauce para sus aspiraciones religiosas y militares en la profesión en las ordenes militares, en este caso en el Temple. Una vez reconocida como cruzada la lucha en la conquista, principalmente a partir de las campañas de Tortosa $(1148)^{109}$ y Lleida (1149), el Temple les proporcionaba una actividad militar igual a la que hasta entonces habían realizado dentro de una idónea organización, al tiempo que procuraba por su salvación en el más allá ${ }^{110}$. El Temple aprovechaba también la experiencia en el arte de la guerra de la nobleza combatiente; no es casual que muchas veces sin una carrera anterior en la Orden, alcanzasen puestos de responsabilidad, como en el ejemplo de Pere II de Queralt. Hay que tener en cuenta también que muchos miembros de las familias nobles - Queralt, Anglesola, Castellnou ${ }^{111}$ - participaron en las empresas de los reyes de la Corona catalano-aragonesa y que esta había asociado a los templarios en sus campañas. Las relaciones de parentesco que tejieron entre ellos, principalmente por vía matrimonial, reforzaron las características comunes: participación en las campañas militares de sus soberanos y protección al Temple.

La carrera de los Timor, principalmente la de Dalmau, es un ejemplo de carrera militar entre Oriente y Occidente: jefe de los turcoples en Chipre y comendador de Barberà. Su vocación guerrera se hace patente cuando después del proceso, no elige retirarse a una institución religiosa, sino que continúa en el entorno del rey Jaume I y participa en sus campañas militares.

No conocemos ningún miembro de la familia Queralt que fuese obispo o abad. En cambio, los cargos eclesiásticos abundan en los linajes de los Rocabertí o los Torroja. Muchos prelados intervinieron en la conquista aportando hombres y recursos a las batallas, como Berenguer de Torroja ${ }^{112}$, hermano del Gran Maestre. Otros ejercieron 
misiones diplomáticas e intervinieron en los asuntos eclesiásticos, como el arzobispo de Tarragona, Guillem de Rocabertí, que presidió el Concilio de Tarragona en el que se absolvió a los templarios catalanes ${ }^{113}$.

El ejemplo de los Queralt muestra una familia, que en sus dos ramas principales Queralt y Timor - proporcionó personajes importantes a la Orden mientras los miembros que no profesaron mantuvieron buenas relaciones con ella.

Finalmente, la trayectoria de los Queralt-Timor podría considerarse un caso aislado o bien puede ser una ventana abierta para reconsiderar la vocación guerrera y laical de los freires ${ }^{114}$ (Fig. 12 y 13).

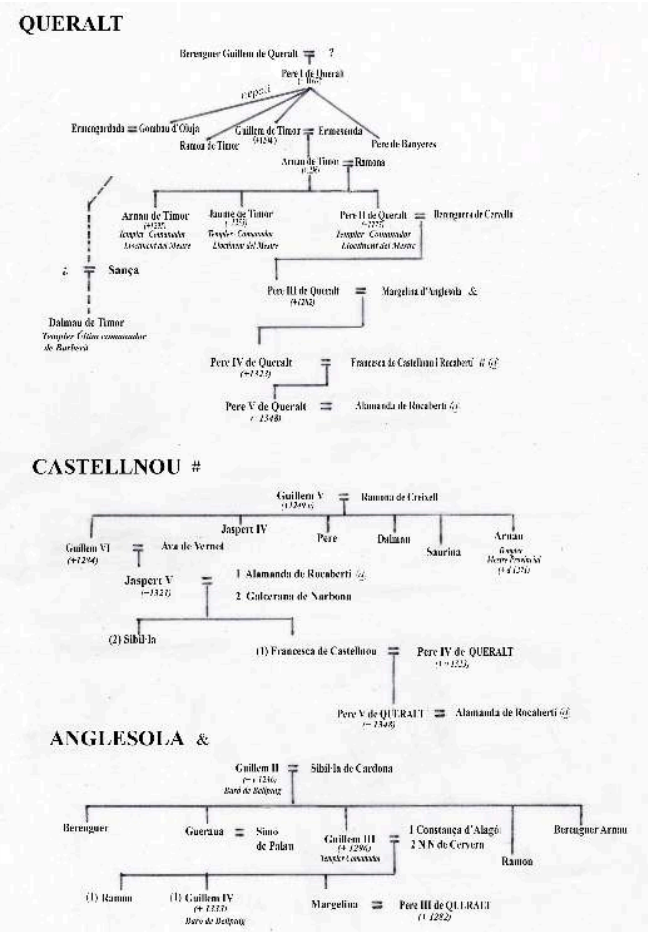

Fig. 12 - Árbol genealógico de los linajes Queralt-Timor, Castellnou y Anglesola (relaciones familiares).

DIBUJO JOAN FUgUET. 


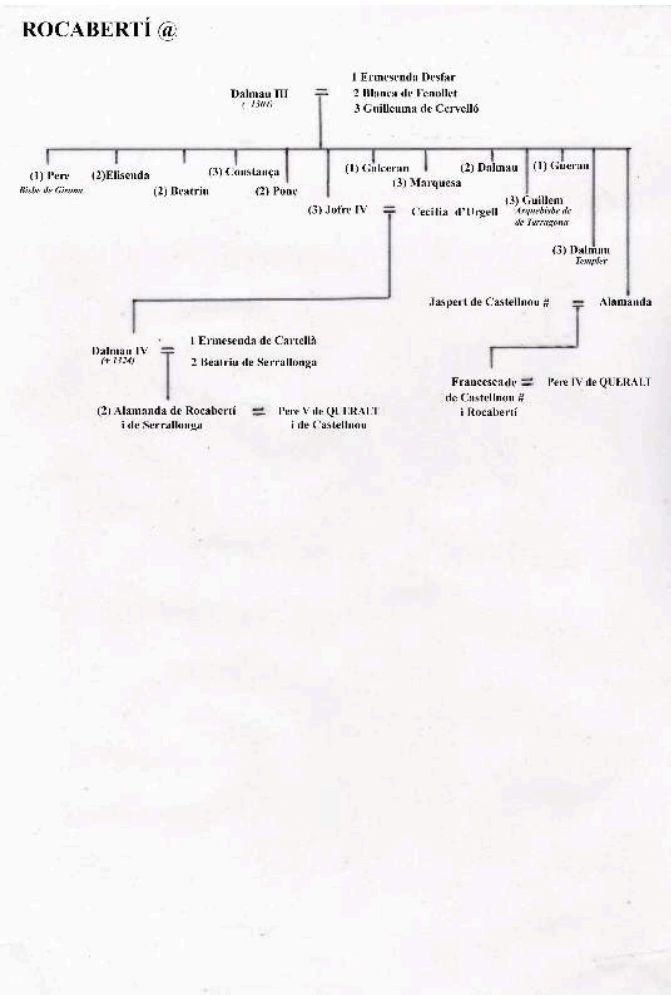

Fig.13 - Árbol genealógico del linaje Rocabertí (relaciones familiares).

DIBUJO JOAN FUgUET.

\section{BIBLIOGRAFÍA}

Fuentes impresas

ALBON, Marquis d' - Cartulaire Général de l'Orde du Temple 1119?-1150. París: Librairie Ancienne, Honoré Champion, Éditeur, 1913.

ALTISENT, Agustí - Diplomatari de Santa Maria de Poblet, vol I, anys 960-1177. Barcelona: Abadia de Poblet; Departament de Cultura de la Generalitat de Catalunya, 1993.

BOFARULL I MASCARó, Pròsper de - Colección de documentos inéditos del Archivo General de la Corona de Aragón. 41 vols., Barcelona: L. Benaiges - José Eusebio Monfort, 1847-1910.

BRUGUERA, Jordi (ed.) - Llibre dels Fets del rei En Jaume. 2 vols. Barcelona: Editorial Barcino, 1991.

FINKE, Heinrich - Papsttum und Untergang des Templerordens, II Band: Quellen, Münster, 1907.

FINKE, Heinrich - Acta Aragonensia: quellen zur Deutschen, Italienischen, Französischen, Spanischen, zur Kirchenund Kulturgeschichte aus der Diplomatischen Korrespondenz Jaymes II: 1291-1327. Berlin, Leipzig: W. Rothschild, 1908.

GONZALVO I BOU, Gener - Les constitucions de Pau i Treva de Catalunya (segles XI i XIII). Barcelona: Departament de Justícia, Generalitat de Catalunya, 1994. 
PALOU I MIQUEL, Hug - Els libri notularum de Santa Coloma de Queralt (1240-1262). 2 vols. Barcelona: Fundació Noguera, 2009.

SANS I TRAVÉ, Josep M. - Col-lecció Diplomàtica de la casa del Temple de Barberà. Barcelona: Departament de Justícia, Generalitat de Catalunya, 1997.

TRETON, Rodrigue - Diplomatari del Masdéu, I-V, Barcelona: Fundació Noguera, Barcelona, 2010.

Estudios

ALTISENT, Agustí - "Un poble de la Catalunya Nova els segles XI i XII. L'Espluga de Francolí de 1079 a 1200”. Anuario de Estudios Medievales 3 (1966), pp. 131-213.

ALVIRA, Martín - "Destruir aquells qui reneguen lo nom de Jhesucrist. El obispo de Barcelona Berenguer de Palou (1212-1241)". in AYALA MARTÍNEZ, Carlos de; PALACIOS ONTALVA, J. Santiago (eds.) - Hombres de religión y guerra. Madrid: Sílex ediciones, 2018, pp. 373-388.

AYALA MARTÍNEZ, Carlos de - "Guerra y Órdenes Militares en la Edad Media: Balance y perspectivas de estudio". in FERNANDES, Isabel Cristina (coord.) - Entre Deus e o Rei. O mundo das ordens militares. Palmela: Município de Palmela- GEsOS, 2018, vol. I, pp. 179-188.

BENET I CLARÀ, Albert - La família Gurb-Queralt (956-1276): senyors de Sallent, Oló, Avinyó, Gurb, Manlleu, Voltregà, Queralt i Santa Coloma de Queralt. Sallent: Institut d'Arqueologia, Història i Ciències Naturals, 1993.

BONET DONATO, María - “Identidad de las hospitalarias en la Corona de Aragón”. Memoria y Civilización. Anuario de Historia 17 (2014), pp. 43-87.

BULST-THIELE, M. Louise - Sacrae domus militiae Templi Hierosolymitani magistri, Untersuchungen zur Geschichte des Templerordens, 1118-1314. Göttingen: Vandenhoeck und Ruprecht, 1974.

BURGTORF, Jochen - The Central Convent of Hospitallers and Templars: History, Organization, and Personnel (1099/1120-1310). Leiden: Brill, 2008.

BUSQUETA I RIU, Joan - "Notícia sobre els Anglesola a la ciutat de Lleida". XXXIX Jornada de Treball. Anglesola: Grup de Recerques de les Terres de Ponent, 2010, pp. 358-368.

CARRAZ, Damien - "Memoire lignagère et archives monastiques: les Bourbouton et la commanderie de Richerenches". in AURELL, Martin (ed.) - Convaincre et persuader: communication et propagande au XII è et XIII ${ }^{\mathrm{e}}$ siècles. Poitiers: Université de Poitiers, 2007, pp. 465-502.

CARRAZ, Damien - "L'affiliation des laics aux commanderies templières et hospitalières de la basse vallée du Rhône (XIIe-XIIIe siècles)". in LUTTRELL, Anthony; TOMMASI, Francesco (eds.) Religiones militares: contributi alla storia degli Ordini Religioso-militari nel medioevo. Città di Castello: Selecta, 2008, pp. 171-190.

CARRAZ, Damien - Damien - "Donation". in BÉRIOU, Nicole; JOSSERAND, Philippe (eds.) - Prier et combatre. Dictionnaire européen des ordres militaires au Moyen Âge. Paris: Fayard, 2009.

CHEVALIER, Marie-Anna (dir.) - Ordres militaires et territorialité au Moyen Âge entre Orient et Occident. París: Geuthner, 2020, pp. 271-310.

CINGOLANI, Stefano Maria - Pere el Gran. Vida, actes, paraula. Barcelona: Editorial Base, 2010.

CID PRIEGO, Carlos - "La escultura de la portada de la iglesia de Santa María de Belloc de Santa Coloma de Queralt”. Boletín Arqueológico 52 (1952), pp. 137-176. 
CID PRIEGO, Carlos - La iglesia de Santa María de Belloc en Santa Coloma de Queralt. Santa Coloma de Queralt: Ayuntamiento de Santa Coloma de Queralt, 1954.

Claverie, Pierre-Vincent - "La contribution des templiers de Catalogne à la defense de la Syrie franque (1290-1310)". in Vermeulen, U.; Van Steenbergen, J. (eds.) - Egipt and Syria in the Fatimid, Ayyubid and Mamluk Eras III. Leuven: Peeters, 2001, pp. 171-192. (Proceedings of the 6th, 7th and 8th International Colloquium organized at the Katholieke Universiteit Leuven in May 1997, 1998 and 1999).

CLAVERIE, Pierre-Vincent - "Un moment clé de l'histoire du Royaume de Majorque: la fin de la vicomté de Castelnou (1321-1369)”. e-Spania [En línea] 29 (Consultado en 5 Noviembre 2020). Disponible en https://doi.org/10.4000/e-spania.27099.

CONILL, Miquel - Heroica vida y exemplares virtudes del Venerable Doctor D. Francisco de Queralt. Cervera: Impremta de la Universitat, 1736.

CORTADA, Juan - El templario y la villana. Crónica del siglo XIV. Barcelona: Imprenta de Brusi, 1840.

COSTA I PARETAS, M. Mercè - “La família Queralt i Santes Creus”. in I Col-loqui d'Història del Monaquisme Català. Santes Creus: Publicacions de l'Arxiu Bibliogràfic de Santes Creus, Vol. I, 1966, pp. 92-109.

CURZI, Gaetano - La pittura dei Templari. Milán: Silvana Editoriale, 2002.

DEMURGER, Alain - "L'aristocrazia laica e gli ordini militari in Francia nel Duecento: l'esempio della Bassa Borgogna". in COLI, Enzo; DE MARCO, Maria; TOMMASI, Francesco (eds.) - Militia Sacra. Gli ordini militari tra Europa e Terrasanta. Perugia: Società Editrice S. Bevignate, 1994, pp. 55-84.

DEMURGER, Alain - Les Templiers. Une chevalerie chrétienne au Moyen Âge. París: Seuil, 2005.

DÍAZ MANTECA, Eugeni - "La venda del castell de Culla al Temple: un procés llarg i dificultós (1303-1388)". in Estudis recollits en el 750è aniversari de la carta de població (1244-1994). Culla: Comissió de Cultura per al 75è aniversari de la carta de població, vol. 2, 1994, pp. 451-481.

DURAN I SANPERE, Agustí - Els retaules de pedra. Vol. I. Monumenta Cataloniae. Barcelona: Ed. Alpha, 1932.

ESPAÑOL BERTRAN, Francesca - L'arquitectura religiosa romànica a la Conca de Barberà i Segarra tarragonina. Montblanc: Centre d'Estudis de la Conca de Barberà, 1991.

FELIU I MONTFORT, Gaspar - “La baronia d'Utxafava (1283-1422)”. Acta Mediaevalia 25 (2003-2004), pp. 257-276.

FERRÉS I ARDERIU, Pere - “Un jove romàntic Ramon Picó i Campanar”. Anuari Verdaguer 12 (2004), pp. 11-80.

FLUVIÀ I ESCORÇA, Armand de - “Rocabertí”. in Gran Enciclopèdia Catalana, 12, Barcelona, 1978, pp. 653-658.

FOREY, Alan J. - The Templars in the ‘Corona de Aragón'. Londres: Oxford University Press, 1973. FOREY, Alan J. - "Recruitment to the Military Order (twelft to mid-fourteenth centuries)". Viator 17 (1986), pp. 139-171.

Forey, Alan J. - "Women and the Military Orders in the twelfth and thirteenth centuries". Studia Monastica 29 (1987), pp. 63-92. 
FOREY, Alan J. - "Letters of the last Two Templars Masters". Nottingham Medieval Studies 45 (2001), pp. 166-167.

FOREY, Alan J. - The fall of the Templars in the crown of Aragon. Ashgate: Aldershot, 2001. FOREY, Alan J. - “A Templar Lordship in Northern Valencia”. in CZAJA, Roman; SARNOWSKY, Jürgen - Selbstbild und Selbstverständnis der Geistlichen Ritterorden. Torun: Wydawnictwo Universytetu Mikolaja Kopernika, 2007, pp. 59-68.

FOREY, Alan J. - "Aragonese templars in the Holy Land and Cyprus in the late thirteenth and early fourteenth centuries". in FERNANDES, Isabel Cristina F. - As Ordens Militares e as Ordens de Cavalaria. Entre o Occidente e o Oriente. Actas do V Encontro sobre Ordens Militares, 15 a 18 de Fevereiro de 2006. Palmela: Câmara Municipal de Palmela-GEsOS, 2009, pp. 451- 461.

FOREY, Alan J. - "The Careers of Templar and Hospitaller Office-Holders in Western Europe during the Twelfth and Thirteenth Centuries". in JOSSERAND, Philippe; OLIVEIRA, Luís F.; CARRAZ, Damien - Élites et ordres militaires au Moyen Âge, Madrid: Casa de Velásquez, 2015, pp. 201-214.

FORT I COGUL, Eufemià - "Pere de Queralt, insigne collaborador de Pere el Gran i egregi amic de Santes Creus”. Boletín Arqueológico 93-96 (1966), pp. 129-139.

FUGUET SANS, Joan- "L'arquitectura dels templers al Camp de Tarragona i la seva aportació als orígens del "gòtic català". XXXV Assemblea Intercomarcal d'Estudiosos de Catalunya. Valls 24, 25 i 26 de novembre de 1989. Estudis Vallencs 28. Catalunya: Institut d'Estudis Vallencs, 1989, pp. 369-401.

FUGUET SANS, Joan - "Santuaris marians de l'Orde del Temple a Catalunya". Afers, fulls de recerca i pensament 10 (1990), pp. 419-433.

FUGUET SANS, Joan - L'arquitectura dels templers a Catalunya. Barcelona: Rafael Dalmau Ed., 1995.

FUGUET SANS, Joan - “Consideracions sobre l'ús de la creu en l'Orde del Temple”. in El temps sota control, Homenatge a F. Xavier Ricomà Vendrell. Tarragona: Diputació de Tarragona, 1997, pp. 295-308.

FUGUET SANS, Joan - "Contribució a l'estudi dels orígens del gòtic meridional: influència de l'arquitectura popular en les construccions templeres i cistercenques catalanes". in Miscel-lània en homenatge a Joan Ainaud de Lasarte. Barcelona: Museu Nacional d'Art de Catalunya-Institut d'Estudis Catalans- Publicacions de l'Abadia de Montserrat, 1998, vol. I, pp. 225-236.

FUGUET SANS, Joan - Templers i hospitalers, II. Guia de les terres de l'Ebre i dels castells templers del Baix Maestrat. Barcelona: Rafael Dalmau Ed., 1998.

FUGUET SANS, Joan - "Les esglésies amb arcs de diafragma de la Catalunya Nova". in BRACONS, Josep; FREIXAS, Pere (coords.) - L'Art Gòtic a Catalunya. Arquitectura I. Catedrals, monestirs i altres edificis religiosos. Barcelona: Enciclopèdia Catalana, 2002, vol. I, pp. 152-159.

FUGUET SANS, Joan - Templers i Hospitalers, IV. Guia de la Catalunya Vella, el Penedès, els comtats del Rosselló i Mallorca. Barcelona: Rafael Dalmau Ed., 2005.

FUGUET SANS, Joan - “Any 1307, un capítol provincial dels templers catalano aragonesos a Sant Francesc de Montblanc”. Foradot 52 (2009), pp. 20-22.

FUGUET SANS, Joan - "Historia y patrimonio artístico de los templarios en Cataluña". Cuadernos del Centro de Estudios de Monzón y Cinca Medio 41 (2015), pp. 139-181. 
FUGUET SANS, Joan; ARTIGAU MIRALLES, Montserrat; FRANCH PAGÈs, Silvia - "La galeria del castell templer de Corbera d'Ebre”. Unicum 2 (2003), pp. 4-15.

FUGUET SANS, Joan; PLAZA ARQUÉ, Carme - “L'ordre de l'Hôpital de Saint-Jean de Jérusalem dans les territoires pyrénéens du nord de la Catalogne et de l'Aragon". in FUGUET SANS, Joan; PLAZA ARQUÉ, Carme; HOFBAUEROVÁ, Vera - Els Queralt a Santa Coloma, arquitectura, art i vida. Santa Coloma: Ajuntament de Santa Coloma, 2010.

FUGUET SANS, Joan; PLAZA ARQUÉ, Carme - "Culto a los santos y lucha contra el Islam en las Órdenes Militares de la Corona catalano-aragonesa”. in CARRAZ, Damien; DEHOUX, Esther (dirs.)

- Images et ornements autour des Ordres Militaires au Moyen Âge. Toulouse: Presses universitaires du Midi, 2016, pp. 36-38.

IGLESIES FORT, Josep - El fogatge de 1553. Estudi i transcripció. Barcelona: Fundació Vives Casajuana, 1979-1980.

JASPERT, Nikolas - "Capta est Dertosa, clavis cristianorum: Tortosa and the Crusades". in PHILLIPS, Jonathan (ed.) - The second crusade - scope and consequences. Manchester: Manchester University Press, 2001, pp. 90-110.

JASPERT, Nikolas - "The election of Arnau de Torroja as ninth Master of the Knights Templar (1180): an enigmatic decision reconsidered". in FERNANDES, Isabel Cristina (coord.) - As Ordens Militares e as Ordens de Cavalaria. Entre o Ocidente e o Oriente. Actas do V Encontro sobre Ordens Militares, 15 a 18 de Fevereiro de 2006. Palmela: Câmara Municipal de Palmela-GEsOS, 2009, pp. 371-398.

JOSSERAND, Philippe - Église et pouvoir dans la Peninsule Ibérique. Les Ordres Militaires dans le Royaume de Castille (1252-1369). Madrid: Casa de Velázquez, 2004.

LAVEDAN, Pierre - L'architecture gothique religieuse en Catalogne, Valence et Baléares. París: Henri Laurens ed., 1935.

LIAÑO MARTÍNEZ, Emma - "Las iglesias góticas de Santa Coloma de Queralt". Aplec de Treballs 2 (1980), pp. 21-50.

MAGNOU, Élisabeth - "Oblature, classe chevalesque et servage dans les maisons méridionales du Temple au XII ${ }^{e}$ siècle”. Annales du Midi 73 (1961), pp. 377-397.

MARCA, Petrus de - Marca Hispanica sive limes Hispanicus. París: 1688.

MARTINELL BRUNET, Cèsar - El monestir de Poblet. Barcelona: Ed. Barcino, 1927.

MARTINELL BRUNET, Cèsar - “Arquitectura mercedaria”. Cuadernos de Arqueología e Historia de la Ciudad 8 (1965), pp. 59-71.

MAS I VIVES, Joan - El teatre a Mallorca a l'època romàntica. Barcelona: Publicacions de l'Abadia de Montserrat, 1986.

MASIÁ DE ROS, Ángeles - Relación castellano-aragonesa desde Jaime II a Pedro el Ceremonioso. Madrid: CSIC, 1994, 2 vols.

MIRAMON, Charles de - Les “donnés” au Moyen Âge: une forme de vie religieuse laïque, v. 1180 v. 1500. Paris: Les Editions du Cerf, 1999.

MIRET I SANS, Joaquim - Les cases de templers y hospitalers en Catalunya. Barcelona: Casa Provincial de Caritat, 1910.

MORERA I LLAURADÓ, Emili - Tarragona cristiana, I. Tarragona: Establecimiento tipográfico de F. Arís e Hijo, 1897. 
MORERA I LLAURADÓ, Emili - "Provincia de Tarragona”. in CARRERAS CANDI, Francesc (dir) Geografia General de Catalunya. Barcelona: Establiment Editorial de Albert Martín, s. d. [1909?].

Nicholson, Helen - "Women in Templar and Hospitaller Commanderies". in Luttrell, Anthony; Pressouyre, Léon (dirs.) - La Commanderie, institution des ordres militaires dans l'Occident médiéval. París: Comité des travaux historiques et scientifiques, 2002, pp. 125-134.

PAGAROLAS SABATER, Laureà - Els templers de les Terres de l'Ebre (Tortosa). De Jaume I fins a l'abolició de l'Orde (1213-1312). 2 vols. Tarragona: Diputació de Tarragona, 1998.

Pié Faidella, Joan - Relación histórica del santuario de Paret Delgada. Tarragona: Tip. de F. Arís e Hijo, 1896.

PLAZA ARQUÉ, Carme - "El Promasó (Masó)". Butlletí Interior. Societat d'Onomàstica 37 (1988), pp. 3-6.

PLAZA ARQUÉ, Carme - “La Masó, un topònim de luxe”. Sis Focs 29 (1989), pp. 3-6.

PONSIC, Pere - “Castellnou”. in Catalunya Romànica, XXV. El Vallespir, El Capcir, El Donasà, La Fenolleda, El Perapertusès. Barcelona, 1996.

RUNCIMAN, Steven - Vísperas sicilianas: una historia del mundo mediterráneo a finales del siglo XIII. Madrid: Alianza Ed., 1979.

SANS I TRAVÉ, Josep M. - “Alguns aspectes de l'establiment dels templers a Catalunya: Barberà”. Quaderns d'Història Tarraconense 1 (1977), pp. 9-59.

SANS I TRAVÉ, Josep M. - “El Rourell, una preceptoria del Temple al Camp de Tarragona (1162?-1248) ”. Butlletí Arqueològic 133-140 (1977), pp. 133-201.

SANS I TRAVÉ, Josep M. - "Pere de Queralt, primer feudatari de l'Espluga de Francolí (1150-1166)". in Universitas Tarraconensis. Revista de Geografia, Història i Filosofia 2 (1977-1978), pp. 25-52.

SANS I TRAVÉ, Josep M. - "La comanda de Vallfogona de Riucorb. Primera part: la creació i formació del patrimoni (segles XII i XIII)”. Quaderns d'Història Tarraconense 2 (1980), pp. 7-54.

SANS I TRAVÉ, Josep M. - "La introducció de l'orde del Temple a Catalunya i la seva organització". in Actes de les Primeres Jornades sobre els Ordes Religioso-Militars als Països Catalans (segles XII-XIX). Tarragona: Diputació de Tarragona, 1994, pp. 17-42.

SANS I TRAVÉ, Josep M. - Fra Arnau de Torroja, Mestre del Temple a Catalunya (1166-1181) i Mestre Major de l'Orde (1181-30 de setembre de 1184). Barcelona: Reial Acadèmia de Bones Lletres de Barcelona, 2006, pp. 12-130.

SCHENK, Jochen G. - "Forms of lay association with the Order of the Temple". Journal of Medieval History 34 (2008), pp. 79-103.

SCHENK, Jochen G. - Templar families. Cambridge: Cambridge University Press, 2015.

SEGURA VALLS, Joan- Historia de la villa de Santa Coloma de Queralt. Barcelona: Imprenta Vicente Magriñá, 1879.

SEGURA VALLS, Joan - "Aplech de documents curiosos e inèdits fahents per la Història de las costums de Catalunya". in Jochs Florals de Barcelona. Barcelona: Estampa de la Renaixensa, 1883.

SEGURA I VALLS, Joan - “Repàs d'un Manual notarial del temps del rey En Jaume I". in Congrés [Ier] d'Història de la Corona d'Aragó, dedicat al Rey en Jaume I y a la seua època. I, Barcelona: Stampa d'en Francisco Altés, 1909, pp. 300-326. 
SEGURA VALLS, Joan - Història de Santa Coloma de Queralt. Refosa i ordenada en la seva ampliació per Joaquim Segura Lamich. $2^{\mathrm{a}}$ ed. Santa Coloma de Queralt, 1971.

SELWOOD, Dominic - Knights of the Cloister. Woodbridge: The Boydell Press, 1999.

SOBREQUÉS VIDAL, Santiago - Els barons de Catalunya. $3^{a}$ ed., Barcelona: Editorial Vicens Vives, 1970.

Tommasi, Francesco - "Uomini e done negli ordini militari di Terrasanta. Per il problema delle case doppie e miste negli ordini giovanita, templare e teutonico (secc. XII-XIV)". in elm, Kaspar; Parisse, Michel (eds.) - Doppelklöster und andere Formen der Symbiose männlicher und weiblicher Religiosen im Mittelalter. Berlin: Duncker et Humblot, 1992. (Berliner Historische Studien, Band 18, Ordensstudien VIII), pp. 177-202.

TORMO y MONZÓ, Elias - "Dictamen de Santa María de Bell-lloch en Santa Coloma de Queralt (Tarragona)”. Boletín Arqueológico año XLIV, época IV, fasc. 3-4 (1944), pp. 58-66.

TORRES, Miquel y SANFELIU, Guiu - "Entre el Corb i l'Ondara. Relacions entre nobles i templers: els Anglesola, els Cervera i els Timor-Queralt”. Actes de la XXXVII Jornada de Treball. Barbens: Grup de Recerques de les Terres de Ponent, 2008, pp. 90-108.

VILAGINÉS SEGURA, Jaume - "Pere de Rovira, un templer del Vallès”. Notes 20 (2005), pp. 43-60.

\section{NOTAS}

1. Véase, entre otros, FOREY, Alan J. - "Recruitment to the Military Order (twelft to midfourteenth centuries)". Viator XVII (1986), pp. 139-171; SCHENK, Jochen G. - Templar families. Cambridge: Cambridge University Press, 2015; SELWOOD, Dominic - Knights of the Cloister. Woodbridge: The Boydell Press, 1999, pp. 100-141; BURGTORF, Jochen - The Central Convent of Hospitallers and Templars: History, Organization, and Personnel (1099/1120-1310). Leiden: Brill, 2008.

2. Sobre las relaciones entre la nobleza y las órdenes hispanas, véase JOSSERAND, Philippe - Église et pouvoir dans la Peninsule Ibérique. Les ordres militaires dans le Royaume de Castille (1252-1369). Madrid: Casa de Velázquez, 2004, pp. 373-455.

3. FOREY, Alan J. - The Templars in the 'Corona de Aragón'. Londres: Oxford University Press, 1973, p. 312; FOREY, Alan J. - "The Careers of Templar and Hospitaller OfficeHolders in Western Europe during the Twelfth and Thirteenth Centuries". in JOSSERAND, Philippe; OLIVEIRA, Luís F.; CARRAZ, Damien - Élites et ordres militaires au Moyen Âge. Madrid: Casa de Velásquez, 2015, p. 205.

4. El linaje Queralt no aparece tampoco en la obra de SOBREQUÉS VIDAL, Santiago - Els barons de Catalunya. $3^{\text {a }}$ ed. Barcelona: Editorial Vicens Vives, 1970.

5. MIRET I SANS, Joaquim - Les cases de templers y hospitalers en Catalunya. Barcelona: Casa Provincial de Caritat, 1910, pp. 23-24; y ALBON, Marquis d'-Cartulaire Général de l'Orde du Temple 1119?-1150. París: Librairie Ancienne, Honoré Champion Éditeur, 1913, doc. n. XXXIII, p. 25, datan este documento en 1130; sin embargo, FOREY, Alan J. - The Templars... cree más probable que fuera redactado en 1131, el día antes de la muerte del conde Ramon Berenguer que es cuando pidió el ingreso en la Orden.

6. Posteriormente amplió el tema SANS I TRAVÉ, Josep M. - “Alguns aspectes de l'establiment dels templers a Catalunya: Barberà”. Quaderns d'Història Tarraconense 1 (1977), pp. 9-59.

7. TRETON, Rodrigue - Diplomatari del Masdéu. Vol. I. Barcelona: Fundació Noguera, pp. 25-27. 
8. FUGUET SANS, Joan - "Historia y patrimonio artístico de los templarios en Cataluña". Cuadernos del Centro de Estudios de Monzón y Cinca Medio 41 (2015), p. 180.

9. Arnau de Torroja aparece en muchos de los documentos de SANS I TRAVÉ, Joseph M. (ed.) Collecció Diplomàtica de la casa del Temple de Barberà. Barcelona: Departament de JustíciaGeneralitat de Catalunya, 1997.

10. La familia Gurb-Queralt fue estudiada de manera definitiva y ejemplar por Benet (cuyo trabajo seguimos aquí) BENET I CLARÀ, Albert - La familia Gurb-Queralt (956-1276): senyors de Sallent, Oló, Avinyó, Gurb, Manlleu, Voltregà, Queralt i Santa Coloma de Queralt. Sallent: Institut d'Arqueologia, Història i Ciències Naturals, 1993.

11. La mayor parte de documentación sobre la familia Queralt se encuentra en el Arxiu de la Corona d'Aragó de Barcelona, Patrimoniales, Fons Queralt; en el Arxiu Comarcal de la Conca de Barberà, Montblanc, Fons Notarial de Santa Coloma de Queralt; en Biblioteca de Catalunya, Barcelona, Reserva, Fons Queralt.

Los Queralt-Timor tuvieron la suerte de ser conocidos gracias a la importante aportación histórica de SEGURA VALLS, Joan - Historia de la villa de Santa Coloma de Queralt. Barcelona: Imprenta Vicente Magriñá, 1879; SEGURA VALLS, Joan - Història de Santa Coloma de Queralt. Refosa i ordenada en la seva ampliació per Joaquim Segura Lamich. $2^{\mathrm{a}}$ ed., Santa Coloma de Queralt, 1971; los trabajos de COSTA I PARETAS, M. Mercè - "La família Queralt i Santes Creus". in I Colloqui d'Història del Monaquisme Català. Santes Creus: Publicacions de l'Arxiu Bibliogràfic de Santes Creus, v. I, 1966, pp. 93-109; y FORT I COGUL, Eufemià - "Pere de Queralt, insigne collaborador de Pere el Gran i egregi amic de Santes Creus". Boletín Arqueológico de Tarragona, 93-96, (1966), pp. 129-139, proporcionan también informaciones sobre algunos aspectos de éste linaje.

12. Era un procedimiento frecuente que una familia noble adoptara como patronímico el nombre del castillo en lugar del de su linaje. Ocurrió con los Queralt, los Torroja, los Cervera...

13. El castillo de Queralt lo tenía en feudo de su hermano Bernat Guillem, continuador de la rama principal de los Gurb-Queralt.

14. MIRET I SANS, Joaquim - Les cases ..., p. 38; BOFARULL I MASCARó, Pròsper de - Colección de documentos inéditos del Archivo de la Corona de Aragón. Vol. IV. Barcelona: José Eusebio Monfort, 1849, doc. n. XI, pp. 29-32; GONZALVO I BOU, Gener - Les constitucions de Pau i Treva de Catalunya (segles XI i XIII). Barcelona: Departament de Justícia-Generalitat de Catalunya, 1994, doc. n. 11, pp. 49-51.

15. Algunos historiadores han confundido este personaje con un miembro de la familia Timor y lo han considerado padre de Pere II de Queralt-Timor, que no pertenecía a los Timor sino a una rama colateral de los Gurb-Queralt (FUGUET SANS, Joan; PLAZA ARQUÉ, Carme; HOFBAUEROVÁ, Vera -Els Queralt a Santa Coloma, arquitectura, art $i$ vida. Santa Coloma: Ajuntament de Santa Coloma, 2010, p. 16).

16. Sobre Pere I de Queralt, veáse SANS I TRAVÉ, Josep M. - "Pere de Queralt, primer feudatari de l'Espluga de Francolí (1150-1166)". Universitas Tarraconensis. Revista de Geografia, Història i Filosofía 2 (1977-1978), pp. 25-52; FORT I COGUL, Eufemià - "Pere de Queralt (...)" ..., pp. 129-139; ALTISENT, Agustí - "Un poble de la Catalunya Nova els segles XI i XII: l'Espluga de Francolí de 1079 a 1200”. Anuario de Estudios Medievales 3 (1966), pp. 142-143.

17. Fueron varios los señores de la Conca de Barberà y tierras vecinas que peregrinaron a la Ciudad Santa. El viaje les proporcionaba además un prestigio social (ALTISENT, Agustí - “Un poble de la Catalunya Nova els segles XI i XII (...)”..., pp. 150-167). 
18. SANS I TRAVÉ, Josep M. - "La comanda de Vallfogona de Riucorb. Primera part: la creació i formació del patrimoni (segles XII i XIII)”. Quaderns d'Història Tarraconense 2 (1980), pp. 7-54.

19. MORERA I LLAURADÓ, Emili - Tarragona cristiana. Vol I. Tarragona: Establecimiento tipográfico de F. Arís e Hijo, 1897, p. 474.

20. SANS I TRAVÉ (ed.) - Collecció diplomática ..., doc. n. 156.

21. Sobre las diferentes casuísticas de las donaciones, véase CARRAZ, Damien -Damien "Donation". in BÉRIOU, Nicole; JOSSERAND, Philippe (eds.) - Prier et combatre. Dictionnaire européen des ordres militaires au Moyen Âge. Paris: Fayard, 2009.

22. Se trata de una posible intervención de Gombau de Oluja y Guillem de Timor en los sucesos acaecidos en Tarragona entre los Aguiló y el arzobispo Guillem de Cervelló. Véase MARCA, Petrus de - Marca Hispanica sive limes Hispanicus. París: 1688, doc. n. 456, col. 1353-1354. Citado por MORERA I LLAURADÓ, Emili - Tarragona cristiana ..., pp. 471-474.

23. SANS I TRAVÉ, Josep M. - "La comanda de Vallfogona de Riucorb (...)" ...; FUGUET SANS, Joan - L'arquitectura dels templers a Catalunya. Barcelona: Rafael Dalmau Ed., 1995, pp. 218-237.

24. MIRET I SANS, Joaquim - Les cases ..., p. 346; SANS I TRAVÉ, Josep M. - "El Rourell, una preceptoria del Temple al Camp de Tarragona (1162?-248)". Butlletí Arqueològic 133-140 (1977), pp. 133-201.

25. FUGUET SANS, Joan - L'arquitectura ..., pp. 237-242.

26. El topónimo Mesó (en la toponimia catalana "Masó") remite a un establecimiento del Temple (PLAZA ARQUÉ, Carme - "El Promasó (Masó)". Butlletí Interior. Societat d'Onomàstica 37 (1988), pp. 3-6: véase también PLAZA ARQUÉ, Carme - “La Masó, un topònim de luxe". Sis Focs 29 (1989).

27. SANS I TRAVÉ, Josep M. - "El Rourell, una preceptoria del Temple al Camp de Tarragona (1162?-248)" ..., p. 188.

28. Ya MIRET I SANS, Joaquim - Les cases ..., p. 248, observó que se trataba de una encomienda especial. Véase FOREY, Alan J. - Women and the Military Orders in the twelfth and thirteenth centuries". Studia Monastica, XXIX (1987), pp. 63-92; NICHOLSON, Helen - "Women in Templar and Hospitaller Commanderies". in LUTTRELL, Anthony; PRESSOUYRE, Léon (dirs.) - La Commanderie, institution des ordres militaires dans l'Occident médiéval. Paris: Comité des travaux historiques et scientifiques, 2002, pp. 125-134; DEMURGER, Alain - Les Templiers. Une chevalerie chrétienne au Moyen Âge. París: Seuil, 2005, pp. 130-132.

29. Véase el documento en TOMMASI, Francesco - "Uomini e done negli ordini militari di Terrasanta. Per il problema delle case doppie e miste negli ordini giovanita, templare e teutonico (secc. XII-XIV)". in ELM, Kaspar; PARISSE, Michel (eds.) - Doppelklöster und andere Formen der Symbiose männlicher und weiblicher Religiosen im Mittelalter.

Berlin: Duncker et Humblot, 1992. (Berliner Historische Studien, Band 18, Ordensstudien VIII), pp. 177-202.

30. SANS I TRAVÉ, Josep M. - "El Rourell, una preceptoria del Temple al Camp de Tarragona (1162?-248)" ..., pp. 182-185.

31. SANS I TRAVÉ, Josep M. - "La introducció de l'orde del Temple a Catalunya i la seva organització”. in Actes de les Primeres Jornades sobre els Ordes Religioso-Militars als Països Catalans (segles XII-XIX). Tarragona: Diputació de Tarragona, 1994, p. 34. 
32. TOMMASI, Francesco - "Uomini e done negli ordini militari di Terrasanta (...)" ..., p. 200, interpreta que Ermengarda fue primero donada y al cabo de un tiempo, ya viuda de Gombau, fue plenamente soror profesa.

33. Remarcan esta ambigüedad NICHOLSON, Helen - "Women in Templar and Hospitaller Commanderies" ..., pp. 126-127 y TOMMASI, Francesco - "Uomini e done negli ordini militari di Terrasanta (...)" ..., p. 200.

34. SANS I TRAVÉ (ed.) - Collecció Diplomàtica ..., doc. n. 191.

35. "quod vobis faciatis michi Berenguer secundum alios donatos qui abitant ibi", SANS I TRAVÉ (ed.) - Collecció Diplomàtica ..., doc. n. 179r.

36. Un caso parecido podría ser el de las hospitalarias de Isot: “... la participación de algunas hermanas se concretó en determinadas acciones, como, por ejemplo, en la recepción de los donados y donadas" (BONET DONATO, María - "Identidad de las hospitalarias en la Corona de Aragón”. Memoria y Civilización. Anuario de Historia 17 (2014), p. 67. Véase también FUGUET SANS, Joan; PLAZA ARQUÉ, Carme - "L'ordre de l'Hôpital de Saint-Jean de Jérusalem dans les territoires pyrénéens du nord de la Catalogne et de l'Aragon". in CHEVALIER, Marie-Anna (dir.) - Ordres militaires et territorialité au Moyen Âge entre Orient et Occident. París: Geuthner, 2020, pp. 277-278.

37. Véase MAGNOU, Élisabeth - "Oblature, classe chevalesque et servage dans les maisons méridionales du Temple au XII ${ }^{\mathrm{e}}$ siècle". Annales du Midi 73 (1961), pp. 377-397; MIRAMON, Charles de - Les "donnés" au Moyen Âge: une forme de vie religieuse laïque, v. 1180 - v. 1500. Paris: Les editions du Serf, 1999; SCHENK, Jochen G. - "Forms of lay association with the Order of the Temple". Journal of Medieval History 34 (2008), pp. 79-103; CARRAZ, Damien - "L'affiliation des laics aux commanderies templières et hospitalières de la basse vallée du Rhône (XIIe-XIIIe siècles)". in LUTTRELL, Anthony; TOMMASI, Francesco (eds.) - Religiones militares: contributi alla storia degli Ordini Religioso-militari nel medioevo, Città di Castello: Selecta, 2008, pp. 171-190; BONET DONATO, María - "Identidad de las hospitalarias en la Corona de Aragón" ..., p. 67.

38. Es probable que este personaje iniciara su carrera en Barberà. Tuvo cargos de responsabilidad en la Orden: en 1227 fue comendador de Horta; en 1231-1233, de Gardeny; en 1234 y 1236, de Villel; en 1240, de Cantavieja; y entre 1243-1245 otra vez en Villel (FOREY, Alan J. - The templars ..., pp. 427-444). Aportó tierras importantes en los dominios que el Temple ya poseía en Vallfogona, SANS I TRAVÉ, Josep M. - “La comanda de Vallfogona de Riucorb (...)” ..., p. 30.

39. SANS I TRAVÉ, Josep M. - "El Rourell, una preceptoria del Temple al Camp de Tarragona (1162?-248)" ..., p. 160.

40. FUGUET SANS, Joan - L'arquitectura..., pp. 141-142.

41. FUGUET SANS, Joan - "L'arquitectura dels templers al Camp de Tarragona i la seva aportació als orígens del "gòtic català". XXXV Assemblea Intercomarcal d'Estudiosos de Catalunya. Valls 24, 25 i 26 de novembre de 1989, Estudis Vallencs, 28. Catalunya: Institut d'Estudis Vallencs, 1989, p. 382; IGLESIES FORT, Josep - El fogatge de 1553. El fogatge de 1553. Estudi i transcripció. 2 vols. Barcelona: Fundació Vives Casajuana, 1979-1980, p. 269.

42. FUGUET SANS, Joan - L'arquitectura..., pp. 243-244.

43. Los pergaminos copiados en el "Cartulari $A B$ de l'arquebisbe Rocaberti" del Arxiu Arxidiocesà de Tarragona, (publicados por SANS I TRAVÉ, Josep M. - Collecció Diplomàtica ...), tan sólo representan una parte mínima de la documentación.

44. "Del féu de Rourell formaren los Templers una preceptoria que depenjava de la encomanda de Barbarà, montant algun establiment en l'eremitori de la Mare de Déu de Paret Delgada, en lo terme de la Selva", in MORERA I LLAURADÓ, Emili - Provincia de Tarragona. Barcelona: Geografia de Catalunya. Dir. F. Carreras y Candi, s. d., p. 348.

45. PIÉ FAIDELLA, Joan - Relación histórica del santuario de Paret Delgada. Tarragona: Tip. de F. Arís e Hijo, 1896, pp. 17-26. 
46. Véase LAVEDAN, Pierre - L'architecture gothique religieuse en Catalogne, Valence et Baléares. París: Henri Laurens (ed.), 1935, p. 72.

47. FUGUET SANS, Joan - L'arquitectura..., pp. 386-395; FUGUET SANS, Joan - "Contribució a l'estudi dels orígens del gòtic meridional: influència de l'arquitectura popular en les construccions templeres i cistercenques catalanes". in Miscellània en homenatge a Joan Ainaud de Lasarte. vol. I., Barcelona: Museu Nacional d'Art de Catalunya. Institut d'Estudis Catalans, Publicacions de l'Abadia de Montserrat, 1998, pp. 225-236; FUGUET SANS, Joan - "Les esglésies amb arcs de diafragma de la Catalunya Nova". in BRACONS, Josep; FREIXAS, Pere (coords.) - L'Art Gòtic a Catalunya. Arquitectura I. Catedrals, monestirs i altres edificis religiosos. Vol. 1. Barcelona: Enciclopèdia Catalana, 2002, pp. 152-159.

48. ACA, Fons Queralt, perg. n. 11. (citado por FUGUET SANS, Joan - L'arquitectura ..., p. 231). Este documento contiene la primera noticia sobre el santuario de Bell-lloc que se convertiría en mausoleo de los Queralt. En 1230, Arnau testó por segunda vez y murió en 1236 (MARTINELL BRUNET, Cèsar - El monestir de Poblet. Barcelona: Ed. Barcino, 1927, p. 142).

49. SEGURA VALLS, Joan - Historia de la villa ..., pp. 39-42.

50. SEGURA VALLS, Joan - Història de Santa Coloma de Queralt. Refosa ..., p. 75.

51. En su testamento manda que sean restituidas las deudas de su mujer Berenguera “quondam" (SEGURA VALLS, Joan - Història de Santa Coloma de Queralt. Refosa ..., p. 75).

52. PALOU I MIQUEL, Hug (ed.).) - Els libri notularum de Santa Coloma de Queralt (1240-1262). Vol. II. Barcelona: Fundació Noguera, 2009, doc. n. 567, p. 724.

53. Aunque quizá no era tan frecuente en la Orden del Temple como en otras órdenes hispanas, el hecho de mantener y transmitir el patrimonio no debía de ser un caso exepcional. Véase JOSSERAND, Philippe - Église et pouvoir ..., pp. 430-433.

54. MIRET I SANS, Joaquim - Les cases..., pp. 528-533; FOREY, Alan J. - The Templars ..., pp. 421-437. Los lugartenientes en la Corona de Aragón solían ser comendadores de las encomiendas más importantes: Monzón, Gardeny y Miravet (FOREY, Alan J. - The Templars ..., p. 314). Así ocurrió con Pere II de Queralt y sus hermanos Jaume y Arnau de Timor.

55. “[446] E, nos tornat a la albergada, vengren a nós (...) el maestre d'Uclés e el bisbe de Barcelona e En Pere de Queralt (qui tenía loch del maestre del Temple)", in BRUGUERA, Jordi (ed.) Llibre dels Fets del rei En Jaume. Barcelona: Editorial Barcino, 1991, vol. II, p. 325.

56. Pagarolas habla de Pere II como uno de los templarios con una de las carreras en el Temple más notables de la Corona de Aragón (PAGAROLAS SABATER, Laureà - Els templers de les Terres de l'Ebre (Tortosa). De Jaume I fins a l'abolició de l'Orde (1213-1312). Tarragona: Diputació de Tarragona I, 1998, p. 68, nota 122.

57. Aunque no se ha podido documentar, es probable que Arnau hubiera intervenido en las luchas contra los musulmanes, BULST-THIELE, M. Louise - Sacrae domus militiae Templi Hierosolymitani magistri, Untersuchungen zur Geschichte des Templerordens, 1118-1314. Göttingen: Vandenhoeck und Ruprecht, 1974, p. 100; Véase también SANS I TRAVÉ, Josep M. - Fra Arnau de Torroja, mestre del Temple a Catalunya (1166.1181) i mestre major de l'Orde (1181-30 de setembre de 1184). Barcelona: Reial Acadèmia de Bones Lletres de Barcelona, 2006, pp. 12-130; JASPERT, Nikolas - "The election of Arnau de Torroja as ninth Master of the Knights Templar (1180): an enigmatic decision reconsidered". in FERNANDES, Isabel Cristina (coord.) - As Ordens Militares e as Ordens de Cavalaria. Entre o Occidente e o Oriente. Actas do V Encontro sobre Ordens Militares, 15 a 18 de Fevreiro de 2006. Palmela: Câmara Municipal de Palmela / GEsOS, 2009, pp. 371-398.

58. Sobre Guillem de Mont-redon, PLADEVALL I FONT, Antoni - "Mont-rodon, Guillem de". in Gran Enciclipèdia Catalana 10. Barcelona: Enciclopèdia Catalana, S. A. 1977, p. 269.

59. SOBREQUÉS VIDAL, Santiago - Els barons ..., pp. 120-123. 
60. FUGUET SANS, Joan; PLAZA ARQUÉ, Carme; HOFBAUEROVÁ, Vera - Els Queralt... , pp. 33-67.

61. FUGUET SANS, Joan - L'arquitectura..., pp. 220-222.

62. FUGUET SANS, Joan; PLAZA ARQUÉ, Carme; HOFBAUEROVÁ, Vera - Els Queralt..., p. 49.

63. FUGUET SANS, Joan - L'arquitectura..., p. 91; FUGUET SANS, Joan; ARTIGAU MIRALLES, Montserrat; FRABCH PAGÈs, Silvia - “La galeria del castell templer de Corbera d'Ebre”. Unicum 2 (2003), pp. 4-15.

64. TORMO y MONZÓ, Elias - "Dictamen de Santa María de Bell-lloch en Santa Coloma de Queralt (Tarragona)". Boletín Arqueológico 44 (1944), pp. 58-66; CID PRIEGO, Carlos - La iglesia de Santa María de Belloc en Santa Coloma de Queralt. Santa Coloma de Queralt: Ayuntamiento de Santa Coloma de Queralt, 1954; MARTINELL BRUNET, Cèsar "Arquitectura mercedaria". Cuadernos de Arqueología e Historia de la Ciudad VIII (1965), pp. 59-71; LIAÑO MARTÍNEZ, Emma - "Las iglesias góticas de Santa Coloma de Queralt". Aplec de Treballs 2 (1980), pp. 21-50; FUGUET SANS, Joan - "Santuaris marians de l'Orde del Temple a Catalunya". Afers, fulls de recerca i pensament 10 (1990), pp. 419-433; y ESPAÑOL BERTRAN, Francesca - L'arquitectura religiosa romànica a la Conca de Barberà $i$ Segarra tarragonina. Montblanc: Centre d'Estudis de la Conca de Barberà, 1991, pp. 273-289.

65. SEGURA I VALLS, Joan - Historia de la villa ..., pp. 42-55; SEGURA I VALLS, Joan - "Repàs d'un Manual notarial del temps del rey En Jaume I". in Congrés [Ier] d'Història de la Corona d'Aragó, dedicat al Rey en Jaume I y a la seua època. Barcelona: Stampa d'en Francisco Altés, 1909, vol. I, pp. 300-326.

66. SEGURA I VALLS, Joan - Historia de la villa..., pp. 46-49, 93.

67. COSTA I PARETAS, Maria Mercè - “La família Queralt i Santes Creus”..., pp. 93-109; FORT I COGUL, Eufemià - “Pere de Queralt (...)”..., pp. 129-139. En Poblet hay un sarcófago de los Queralt (FUGUET SANS, Joan; PLAZA ARQUÉ, Carme; HOFBAUEROVÁ, Vera - Els Queralt ..., pp. 119-121).

68. Sin embargo, su hijo Pere III decidió ser enterrado en Santes Creus, igual que su soberano, Pere el Gran, del que fue uno de los principales colaboradores.

69. El estudio más completo sobre la puerta se debe a CID PRIEGO, Carlos - "La escultura de la portada de la iglesia de Santa María de Belloc de Santa Coloma de Queralt”. Boletín Arqueológico 52 (1952), pp. 137-176.

70. La cruz tiene a su vez valor religioso y heráldico, de pertenencia a la Orden (FUGUET SANS, Joan -“Consideracions sobre l'ús de la creu en l'Orde del Temple". in El temps sota control, Homenatge a F. Xavier Ricomà Vendrell. Tarragona: Diputació de Tarragona, 1997, pp. 295-308). Las cruces del castillo de Santa Coloma y de Bell-lloc pertenecen al siglo XIII cuando el Temple empieza a usarlas en territorio de la Corona (en Corbera y Peníscola: FUGUET SANS, Joan Templers i hospitalers, II. Guia de les terres de l'Ebre i dels castells templers del Baix Maestrat. Barcelona: Rafael Dalmau Ed., 1998, pp. 94-98 y pp. 53-55; en Mallorca: FUGUET SANS, Joan - Templers $i$ Hospitalers, IV. Guia de la Catalunya Vella, el Penedès, els comtats del Rosselló i Mallorca. Barcelona: Rafael Dalmau Ed., 2005, pp. 76-77).

71. CID PRIEGO, Carlos - La iglesia de Santa María ..., p. 43.

72. “... túnica quasi fins als talons, ab mànegues estretes com ajustat, falda poch folgada, cenyida la cintura ab una corretja; y al cap cucurulla" (SEGURA VALLS, Joan - "Aplech de documents curiosos e inèdits fahents per la Història de las costums de Catalunya". in Jochs Florals de Barcelona. Barcelona: Estampa de la Renaixensa, 1883, p. 139).

73. CONILL, Miquel - Heroica vida y exemplares virtudes del Venerable Doctor D. Francisco de Queralt. Cervera: Impremta de la Universitat, 1736, p. 7. También podría tratarse de una ficción construida a posteriori, ya que la obra es un panegírico dirigido a los Queralt.

74. En 1869 Ramon Picó i Campanar estrenó en Barcelona una obra de teatro en catalán con el título Cor de Roure. La obra contiene elementos históricos y legendarios y nunca se menciona la 
relación de Pere II con la Orden del Temple. Véase MAS I VIVES, Joan - El teatre a Mallorca a l'època romàntica. Barcelona: Publicacions de l'Abadia de Montserrat, 1986, pp. 325-326; FERRÉS I ARDERIU, Pere - “Un jove romàntic Ramon Picó i Campanar”. Anuari Verdaguer 12 (2004), pp. 11-80.

75. CURZI, Gaetano - La pittura dei Templari. Milán: Silvana Editoriale, 2002, p. 46.

76. FUGUET, Joan y PLAZA, Carme - "Culto a los santos y lucha contra el Islam en las Órdenes Militares de la Corona catalano-aragonesa". in CARRAZ, Damien; DEHOUX, Esther (dirs.) - Images et ornements autour des Ordres Militaires au Moyen Âge. Toulouse: Presses universitaires du Midi, 2016, pp. 36-38.

77. TORMO y MONZÓ, Elías - Dictamen..., pp. 58-66.

78. FOREY, Alan J. - The templars..., pp. 421-437.

79. FOREY, Alan J. - The templars ..., p. 414, Doc. XLIV ... Et frater Dalmatius de Timor torcuplerius. Los turcoples formaban un cuerpo de caballería ligera que estaba al servicio sobretodo de las órdenes militares establecidas en Chipre, Jerusalén, Rodas, etc., durante las Cruzadas.

80. MIRET I SANS, Joaquim - Les cases ..., p. 517; FOREY, Alan J. - The Templars ..., p. 426.

81. FOREY Alan J. - The fall of the Templars in the crown of Aragon. Aldershot: Ashgate, 2001, p. 40.

82. "naturalem nostrum" (FOREY, Alan J. - "Letters of the last Two Templars Masters". Nottingham Medieval Studies 45 (2001), pp. 166-167) y quizá hijo ilegítimo de Jaime II

(FINKE, Heinrich - Acta Aragonensia, II Nächtrage, reprint 621 (citado por BURGTORF, Jochen - The Central Convent ..., p. 427).

83. FOREY, Alan J. - "Letters of the last Two Templars Masters" ..., p. 148.

84. FOREY Alan J. - The fall of the Templars ..., pp. 222-227.

85. RUNCIMAN, Steven - Vísperas sicilianas: una historia del mundo mediterráneo a finales del siglo XIII. Madrid: Alianza Ed., 1979; CINGOLANI, Stefano Maria - Pere el Gran. Vida, actes, paraula. Barcelona: Editorial Base, 2010.

86. MIRET I SANS, Joaquim - Les cases ..., pp. 154-155 y pp. 347-348. BUSQUETA I RIU, Joan - "Notícia sobre els Anglesola a la ciutat de Lleida". XXXIX Jornada de Treball. Anglesola: Grup de Recerques de les Terres de Ponent, 2010, pp. 366 -368; TORRES, Miquel; SANFELIU, Guiu - "Entre el Corb i l'Ondara. Relacions entre nobles i templers: els Anglesola, els Cervera i els Timor-Queralt". Actes de la XXXVII Jornada de Treball. Barbens: Grup de Recerques de les Terres de Ponent, 2008, pp. 98-100.

87. MIRET I SANS, Joaquim - Les cases ..., pp. 516 y 314.

88. FOREY, Alan J., - The templars ..., pp. 421-437.

89. MIRET I SANS, Joaquim - Les cases ..., p. 444. Hay una cierta confusión entre Guillem II y Guillem III de Anglesola. Teniendo en cuenta la fecha de la muerte de Guillem II, 1236, creemos que el templario era Guillem III ya que es comendador de varias encomiendas hasta 1261.

90. Simó era hijo de Ramon de Palau y Eliarda de Torroja. Los Torroja dominaron la Espluga de Francolí por el matrimonio de Ramon II de Torroja con Gaia de Cervera (ALTISENT, Agustí - "Un poble de la Catalunya Nova els segles XI i XII (...)” ..., p. 153). Ramon era del linaje del Gran Maestre Arnau de Torroja. Véase también SOBREQUÉS VIDAL, Santiago - Els barons ..., pp. 100-101.

91. MIRET I SANS, Joaquim - Les cases ..., pp. 313-316. Sibila fue la esposa del vizconde de Ampurias y madre del templario Hug de Ampurias, que fue hecho prisionero en la toma de Trípoli el 1289 (CLAVERIE, Pierre-Vincent - "La contribution des templiers de Catalogne à la defense de la Syrie franque (1290-1310)". in VERMEULEN, U.; VAN STEENBERGEN, J. (eds.) - Egipt and Syria in the Fatimid, Ayyubid and Mamluk Eras III. Leuven: Peeters, 2001, p. 174 (Proceedings of the 6th, 7th and 8th International Colloquium organized at the Katholieke Universiteit Leuven in May 1997, 1998 and 1999). 
92. FOREY, Alan J. - "A Templar Lordship in Northern Valencia". in CZAJA, Roman; SARNOWSKY, Jürgen - Selbstbild und Selbstverständnis der Geistlichen Ritterorden. Torun: Wydawnictwo Universytetu Mikolaja Kopernika, 2007, pp. 59-68; pp. 59-68; DÍAZ MANTECA, Eugeni - "La venda del castell de Culla al Temple: un procés llarg i dificultós (1303-1388)". in Estudis recollits en el 750̀ aniversari de la carta de població (1244-1994). Culla: Comissió de Cultura per al $750^{\mathrm{e}}$ aniversari de la carta de població, vol. 2, 1994, pp. 451-481.

93. FUGUET SANS, Joan - "Any 1307, un capítol provincial dels templers catalanoaragonesos a Sant Francesc de Montblanc". Foradot 52 (2009), pp. 20-22.

94. Probablemente, a la rama Anglesola - Utxafava. Véase FELIU I MONTFORT, Gaspar - "La baronia d'Utxafava (1283-1422). Acta Mediaevalia 25 (2003-2004), pp. 262. Guillem III, el templario, pertenecía a la rama de los Anglesola - Bellpuig.

95. FUGUET SANS, Joan - "Any 1307, un capítol provincial dels templers (...)" ..., pp. 20-22. Ramon de Anglesola era hijo de Galceran de Anglesola, quien, gracias a su rango, intercedió por él durante el sitio de Miravet (FOREY, Alan J. - The fall of the Templars..., p. 91).

96. FOREY, Alan J. -The fall of the Templars ..., p. 214.

97. FINKE, Heinrich - Papsttum und Untergang des Templerordens, II Band: Quellen, Münster, 1907, p. 249.

98. Yace junto a su esposo, Pere IV de Queralt, en el magnífico mausoleo gòtico (siglo XIV) de la capilla norte de la iglesia de Bell-lloc.

99. CLAVERIE, Pierre-Vincent - "Un moment clé de l'histoire du Royaume de Majorque: la fin de la vicomté de Castelnou (1321-1369)". e-Spania [En línea] 29 (Consultado en 5 Noviembre 2020). Disponible en https://doi.org/10.4000/e-spania.27099 , p. 3.

100. MASIÁ, DE ROS, Ángeles - Relación castellano-aragonesa desde Jaime II a Pedro el Ceremonioso. Madrid: CSIC, vol. 1, 1994, pp. 162-163.

101. MIRET I SANS, Joaquim - Les cases ... p. 515; FOREY Alan J. - The templars ..., p. 420.

102. PONSIC, Pere - "Castellnou". in Catalunya Romànica, XXV. El Vallespir, El Capcir, El Donasà, La Fenolleda, El Perapertusès. Barcelona, 1996, pp. 186; CLAVERIE, Pierre-Vincent - "Un moment clé de l'histoire du Royaume de Majorque (...)" ..., p. 4.

103. FLUVIÀ I ESCORÇA, Armand de - "Rocabertí". in Gran Enciclopèdia Catalana. Vol. 12. Barcelona: [s.e.], 1978, pp. 653-658. Agradecemos a Pere Martell sus comentarios sobre Francesca de Castellnou.

104. FOREY Alan J. - The fall of the Templars ..., pp. 228-229.

105. Sobre las negociaciones dirigidas por el rey Jaume II para liberar a Dalmau de Rocabertí, véase CLAVERIE, Pierre-Vincent - "La contribution des templiers de Catalogne à la defense de la Syrie franque (1290-1310)". in VERMEULEN, U.; VAN STEENBERGEN, J. (eds.) - Egipt and Syria in the Fatimid, Ayyubid and Mamluk Eras. III. Leuven: Peeters, 2001 (Proceedings of the 6th, 7th and 8th International Colloquium organized at the Katholieke Universiteit Leuven in May 1997, 1998 and 1999), pp. 185-188.

106. Para tomar el hábito del Temple un casado era necesario el consentimiento de la esposa, que debía firmar la escritura del compromiso con la Orden [MIRET I SANS, Joaquim - Les cases..., p 335. Véase también FOREY, Alan J. - "Recruitement". in BÉRIOU, Nicole; JOSSERAND, Philippe (eds.) Prier et combatre. Dictionnaire européen des ordres militaires au Moyen Âge. Paris: Fayard, 2009].

107. Es el caso del Maestre Provincial Pere de Rovira [VILAGINÉS SEGURA, Jaume - "Pere de Rovira, un templer de Vallès". Notes 20 (2005), p. 50], quien también en 1145 influyó en la donación a la Orden de Nicolás, hijo de Hugo de Bourbouton (ALBON, Marquis d' - Cartulaire Général, doc. n. XXXLXXI, p. 237). Sobre los Bourbouton y la encomienda de Richerenches, véase 
CARRAZ, Damien - "Memoire lignagère et archives monastiques: les Bourbouton et la commanderie de Richerenches". in AURELL, Martin (ed.) - Convaincre et persuader: communication

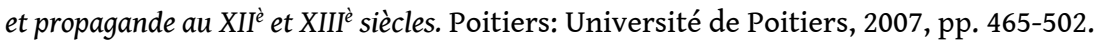

108. DÍAZ MANTECA, Eugeni - "La venda del castell de Culla al Temple: un procés llarg i dificultós (1303-1388)". in Estudis recollits en el 750 è aniversari de la carta de població (1244-1994). Culla: Comissió de Cultura per al 75è aniversari de la carta de població, vol. 2, 1994, pp. 451-481; FOREY, Alan J. - “A Templar Lordship in Northern Valencia”. in CZAJA, Roman; SARNOWSKY, Jürgen (eds.) - Selbstbild und Selbstverständnis der Geistlichen Ritterorden. Torun: Wydawnictwo Universytetu Mikolaja Kopernika, 2007, pp. 59-68.

109. Véase JASPERT, Nikolas - "Capta est Dertosa, clavis cristianorum: Tortosa and the Crusades". in PHILLIPS, Jonathan (ed.) - The second crusade - scope and consequences. Manchester: Manchester University Press, 2001, pp. 90-110.

110. DEMURGER, Alain - "L'aristocrazia laica e gli ordini militari in Francia nel Duecento: l'esempio della Bassa Borgogna". in COLI, Enzo; DE MARCO, Maria; TOMMASI, Francesco (eds.) Militia Sacra. Gli ordini militari tra Europa e Terrasanta. Perugia: Società Editrice S. Bevignate, 1994, p. 66.

111. CINGOLANI, Stefano Maria - Pere el Gran ..., pp. 178-179.

112. El ejemplo paradigmático sería el obispo de Barcelona Berenguer de Palou (ALVIRA, Martín - "Destruir aquells qui reneguen lo nom de Jhesucrist. El obispo de Barcelona Berenguer de Palou (1212-1241)". in AYALA MARTÍNEZ, Carlos de; PALACIOS ONTALVA, J. Santiago (eds.) - Hombres de religión y guerra. Madrid: Sílex ediciones, 2018, pp. 373-388.)

113. FOREY, Alan J. - The fall of the Templars ..., p. 215.

114. "es necesario desterrar de manera definitiva la equívoca etiqueta de "monjes soldados", que enturbia más que aclara" (AYALA MARTÍNEZ, Carlos de - "Guerra y Órdenes Militares en la Edad Media: Balance y perspectivas de estudio". in FERNANDES, Isabel Cristina F. (ed.) - Entre Deus e o Rei. $O$ mundo das ordens militares. Palmela: Município de Palmela; GEsOS, 2018, I, p. 186).

\section{RESÚMENES}

La encomienda del Temple de Barberà (Tarragona) fue una de las principales de la Corona de Aragón, gracias en parte a la colaboración de una de las "familias templarias" más notables de Catalunya: los Queralt-Timor de Santa Coloma. Desde el origen de la encomienda, últimas décadas del siglo s. XII, fueron sus principales benefactores y, más adelante, dieron a la Milicia caballeros de primer rango (Pere II de Queralt, Jaume de Timor, Arnau de Timor, Dalmau de Timor... Todos guerreros de vocación participaron activamente en las conquistas que llevó a cabo la monarquía en el siglo XIII. Pero además, la familia Queralt desarrolló una política matrimonial constante que la emparentaría con diferentes linajes principales del país, así mismo relacionados con el Temple: los Castellnou, los Anglesola, los Rocabertí... Este artículo se interesa particularmente por la vida y las actividades de estos personajes con intención reivindicativa y deseo de situarlos en el lugar que merecen en la historia del Temple.

The commandery of the Temple of Barbera (Tarragona) was one of the leading ones of the Crown of Aragon, thanks in part to the collaboration of one of the most notable 'Templar families': 
Queralt-Timor of Santa Coloma. From the beginning of this commandery in the last decades of the twelfth century, they had been its main benefactors and, later on, provided the Militia with knights of the first rank (Pere II de Queralt, Jaume de Timor, Arnau de Timor, Dalmau de Timor...). They were all professional warriors and took an active part in the conquests which the monarchy carried out in the thirteenth century. But in addition, the Queralt family developed a continuous matrimonial policy which linked it by marriage to the different main lineages of the country, also connected to the Temple: Castellnou, Anglesola, Rocaberti... This article is particularly interested in the life and activities of these individuals with the intention of reevaluating their contribution and giving them the place they deserve in the history of the Temple.

\section{ÍNDICE}

Keywords: Temple, noble families, Catalonia

Palabras claves: Temple, Linajes nobiliarios, Cataluña

\section{AUTORES}

\section{JOAN FUGUET SANS}

Universidad de Barcelona, Facultad de Filosofia y Letras, Departamento de Historia del Arte, 08007 Barcelona, España. joan@fuguet.org. https://orcid.org/0000-0002-5153-4390

\section{CARME PLAZA ARQUÉ}

Universidad de Barcelona, Facultad de Filosofia y Letras, Departamento de Historia del Arte, 08007 Barcelona, España. carmeplaza@fuguet.org 